\title{
OS LANTANÍDEOS NAS REDES METALORGÂNICAS: UMA NOVA CLASSE DE MATERIAIS POROSOS
}

\author{
Ayla R. B. S. Galaço ${ }^{a}$, Juliana F. Lima ${ }^{\mathrm{b}}$ e Osvaldo A. Serra ${ }^{\mathrm{a}, \mathrm{c}, *}$ \\ a'Departamento de Química, Faculdade de Filosofia, Ciências e Letras de Ribeirão Preto, Universidade de São Paulo, Av. Bandeirantes, \\ 3900, 14040-901 Ribeirão Preto - SP, Brasil \\ bDepartamento de Química Geral e Inorgânica, Instituto de Química, Universidade do Estado do Rio de Janeiro, Rua São Francisco \\ Xavier, 524, 20550-900 Rio de Janeiro - RJ, Brasil \\ ${ }^{c}$ Centro de Ciências Naturais e Humanas, Universidade Federal do ABC, Av. dos Estados, 5001, 09210-580 Santo André - SP, Brasil
}

Recebido em 01/02/2018; aceito em 21/02/2018; publicado na web em 21/03/2018

\begin{abstract}
LANTHANOIDS IN THE METAL-ORGANIC FRAMEWORKS: A NEW CLASS OF POROUS MATERIALS. Lanthanoid organic frameworks (LOFs) stand out as an important class of functional materials. The possibility to employ a great range of metals and ligands lead to the formation of varied and highly porous structures, with diverse applications. The presence of lanthanoid ions favours the improvement of the optical, magnetic and redox properties of MOFs. This review aims to demonstrate the state of the art of LOFs, emphasizing the chemical properties of trivalent lanthanoid ions and the carboxylic based-ligands used in their construction, as well as the main characterization methods and outstanding applications as gas storage, permanent magnets, catalysis, luminescence, drug delivery and so on.
\end{abstract}

Keywords: rare earths; MOFs; LOFs; lanthanoids; multifunctional materials.

\section{INTRODUÇÃO}

\section{Introdução às redes metalorgânicas (MOFs)}

Os polímeros de coordenação, conhecidos hoje como MOFs (do termo em inglês metal-organic frameworks), são sistemas formados por unidades primárias de construção, as quais são constituídas por íons metálicos e os ligantes orgânicos polidentados que interagem por meio de ligações de coordenação. ${ }^{1,2} \mathrm{~A}$ descoberta dos primeiros compostos denominados à época como "polímeros de coordenação" foi atribuída a Tomic, que em 1965 publicou o primeiro trabalho sobre este novo tipo de material. ${ }^{3}$ Os compostos sintetizados eram constituídos por ácidos carboxílicos aromáticos e íons metálicos, tais como zinco, ferro e níquel, os quais apresentavam como principal característica elevada estabilidade térmica. No mesmo ano, Biondi e seus colaboradores relataram o composto tricianometaneto de cobre(II), tendo-o classificado como material polimérico cristalino. ${ }^{4}$

A pesquisa sobre polímeros de coordenação começou a aumentar consideravelmente a partir do início dos anos 90. Até meados dessa década a investigação e desenvolvimento eram centrados principalmente em dois tipos de materiais porosos, as zeólitas (sólidos porosos inorgânicos) e os carvões ativados. Estes novos materiais porosos, as MOFs, termo inicialmente cunhado por Yaghi ${ }^{5}$ em 1995, têm atraído atenção tanto no campo da pesquisa acadêmica quanto no tecnológico devido suas aplicações em armazenamento de gases, separação, imãs permanentes, luminescência, catálise heterogênea, sensores químicos, drug-delivery, imagem biomédica, entre outros. ${ }^{6-9}$

Os materiais porosos possuem grande área superficial que os tornam capazes de adsorverem pequenas moléculas ou íons em seu interior. Eles apresentam como os clássicos materiais porosos (ex. carbono ativado, sílica-gel, zeólitas e sílicas mesoporosas), características relevantes como tamanho uniforme do poro e grande área superficial interna.

O volume de trabalhos publicados em revistas científicas nacionais e internacionais na área que envolve o desenvolvimento de novas redes

*e-mail: osaserra@usp.br metalorgânicas, polímeros de coordenação ou MOFs têm sofrido um crescimento exponencial, como apresentado na Figura 1. Isso se deve à versatilidade dos materiais sintetizados a partir da vasta gama de metais e ligantes disponíveis. As MOFs fazem parte de uma das classes de materiais recentes da química supramolecular e a grande motivação dos grupos de investigação deste tema é o desenvolvimento de novas estruturas que possuam características específicas que lhes permitam, por sua vez, ter uma ampla gama de aplicabilidade.

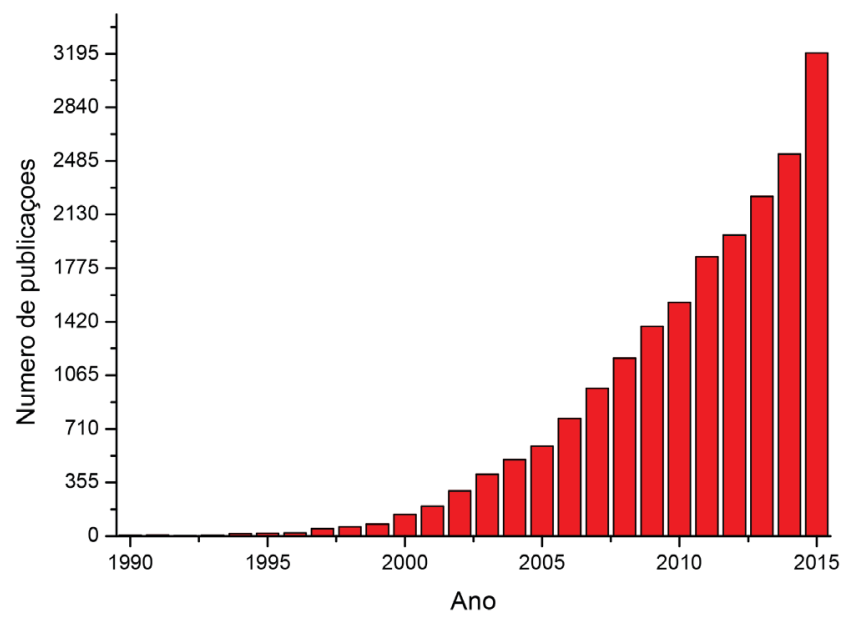

Figura 1. Número de publicações científicas com o termo "metal-organic frameworks" presentes em "tópicos" até 2015. Construído a partir da ISI Web of Science

A síntese das MOFs acontece por um processo de automontagem, ${ }^{10}$ que pode ser pensado como um "jogo de construção", evidenciado na Figura 2. A maior dificuldade consiste na escolha dos espaçadores, que devem ser produtos facilmente sintetizados e que possuam afinidade química com o metal escolhido. A síntese deve ser realizada em condições suaves para manter a funcionalidade e conformação dos ligantes orgânicos, mas em condições reativas o bastante para promover as ligações metal-ligante e ligante-ligante. 

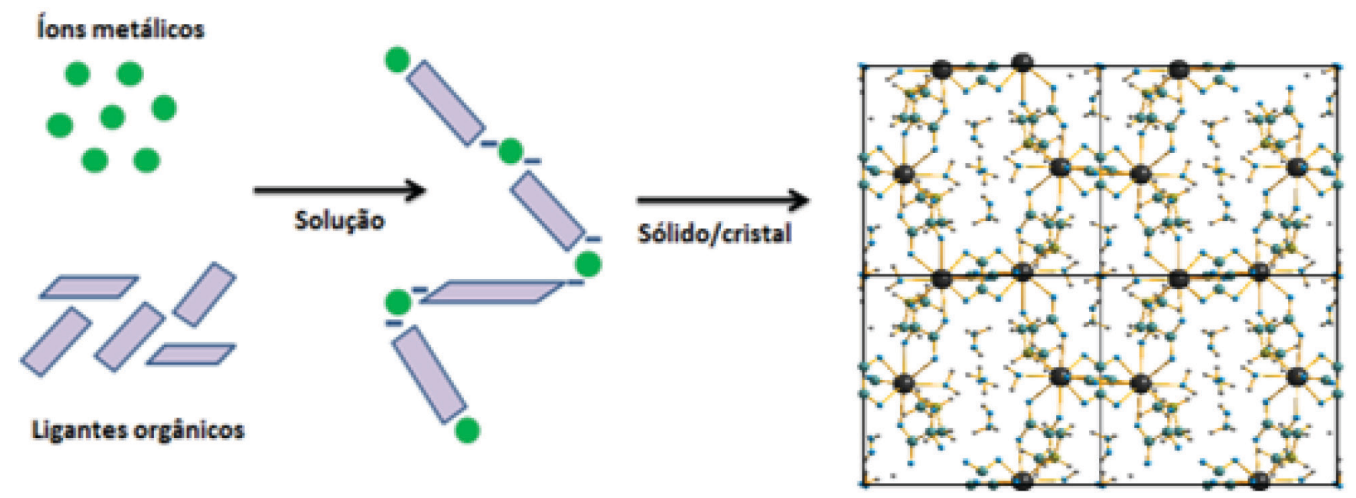

Figura 2. Ilustração do processo de formação dos polímeros de coordenação, conhecidos como MOFs

As MOFs, estruturas supramoleculares, podem se apresentar em uma (1D), duas (2D) ou três (3D) dimensões. O número de coordenação, que varia de acordo com o metal, pode controlar a geometria da estrutura. Os ligantes são comumente polidentados, os quais possuem átomos doadores de elevada densidade eletrônica, como oxigênio e nitrogênio, provenientes de carboxilatos, piridinas e imidazóis, em sua grande maioria. Estes ligantes podem ter grande variedade de forma, rigidez, tamanho e números de átomos doadores. De acordo com o tamanho do ligante é possível controlar o tamanho dos poros. Além disso, a geometria do componente orgânico pode influenciar a topologia do composto: ligantes alifáticos flexíveis produzem estruturas mais densas, ${ }^{11-15}$ enquanto que espécies rígidas ou conjugadas podem promover topologias mais abertas e robustas. ${ }^{16-20}$

Ao contrário das MOFs com metais de transição, em que a geometria da estrutura é primeiramente dependente da configuração eletrônica, os lantanídeos (Ln) com suas orbitais-f blindadas agem como ácidos duros, fazendo com que o tamanho do cátion seja o principal fator na coordenação. Os lantanídeos possuem elevados números de coordenação ( 6 a 12) e geometrias flexíveis, o que torna a reprodução destes materiais extremamente complicada, visto que na maioria dos casos obtém-se uma mistura de estruturas químicas ligeiramente diferentes. Além disso, produzir materiais porosos é um desafio, pois os valores da entalpia sempre serão a favor de um material mais denso. As fracas interações facilitam a remoção das espécies contidas nas redes sem ruptura da estrutura. Assim, a formação de sólidos porosos com centros ácidos (Lewis) pode ser utilizada para catálise.

Em 1999, Yaghi ${ }^{21}$ reportou a síntese da primeira LOF (Lanthanoid Organic Frameworks), contendo íons $\mathrm{Tb}^{3+}$ e o ligante benzeno-1,4-dicarboxilato (bdc $\left.{ }^{2-}\right),\left\{\left[\mathrm{Tb}(\mathrm{bdc})\left(\mathrm{NO}_{3}\right)\right] \cdot 2 \mathrm{dmf}\right\}_{n}$. De acordo com os dados obtidos por difração de raios $\mathrm{X}$ de monocristal (SDRX), os íons $\mathrm{Tb}^{3+}$ estão ligados aos átomos de oxigênio provenientes dos grupos carboxilatos do ligante, resultando em uma rede polimérica 3-D e conferindo estabilidade térmica até 450 ${ }^{\circ} \mathrm{C}$, como visto na Figura 3. Ao ser colocado em água obtêm-se de forma irreversível outro material, o $\left[\mathrm{Tb}_{2}\left(\mathrm{H}_{2} \mathrm{O}\right)_{4}(\mathrm{bdc})_{3}\right]_{n}$, que possui uma estrutura estendida 1D. ${ }^{19}$

Em 1885, nas praias de Prado-BA, as Terras Raras (TR) começaram a ser exploradas. Até 1896 , a retirada era gratuita, com o pretexto de ser usada como lastro dos navios, que não poderiam voltar vazios à Europa ou aos Estados Unidos..$^{22}$ De acordo com Serra, a pesquisa em TR nas universidades brasileiras está dispersa pelo território nacional. A maior parte dos trabalhos publicados, na área de química, concentram-se em materiais luminescentes e magnéticos. Na Figura 4 é possível observar uma visão geral da distribuição da produção científica da última década no campo de luminescência de lantanídeos em diferentes estados e cidades do Brasil. ${ }^{23,24}$

O primeiro passo no planejamento da síntese das LOFs refere-se

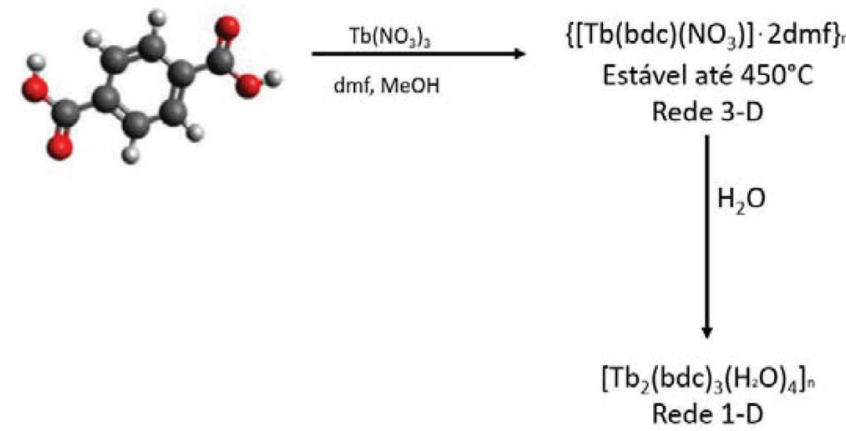

Figura 3. Esquema da formação de LOFs contendo o ligante bdc ${ }^{2-}$ e sua modificação em presença de água $(3-D \rightarrow 1-D)$. Adaptação das referências 18 e 21

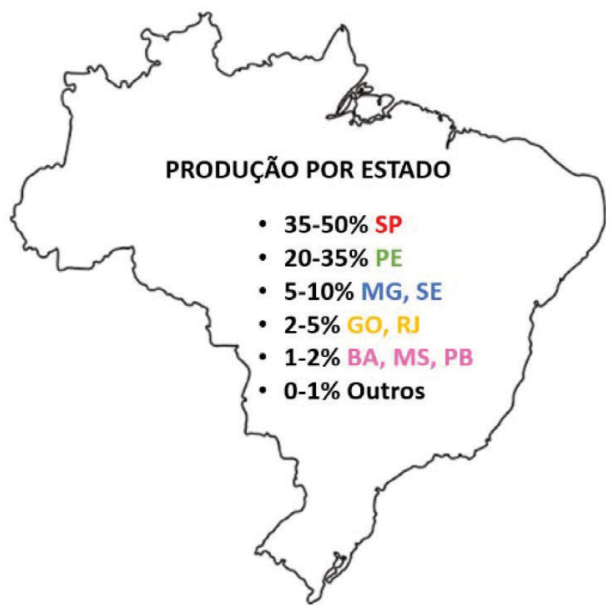

Figura 4. Distribuição da produção cientifica (235 publicações) no campo de luminescência de lantanídeos na década (2005-2014) em diferentes regiões do Brasil. Adaptado da referência 23

à escolha do ligante a ser utilizado. Estes devem, preferencialmente, serem rígidos e direcionais. Além disso devem satisfazer a natureza oxofílica dos lantanídeos. De acordo com Pagis, ${ }^{25}$ observou-se que em variados casos, aumentando o número de anéis aromáticos no ligante há também um aumento da estabilidade térmica da rede porosa formada.

Nas sínteses de LOFs, o sal do lantanídeo (ou óxido) e o ligante carboxilado são combinados na estequiometria desejada. As reações normalmente acontecem acima de $120^{\circ} \mathrm{C}$ quando os ácidos se tornam fracamente solúveis. Em alguns casos, uma base é necessária para desprotonar o ligante, parcial ou totalmente. O processo ocorre principalmente em água, solventes apróticos polares (dmf, def ou dmso) ou em suas misturas. ${ }^{26-28}$ 


\section{PROPRIEDADES DOS ÍONS LANTANÍDEOS TRIVALENTES}

Embora os 15 elementos que compõem os lantanídeos (La-Lu) sejam quimicamente semelhantes, estes mostram grande diferença quanto às propriedades ópticas, magnéticas ou de oxirredução, o que lhes conferem uma vasta aplicação, as quais vão de luminóforos, ${ }^{29,30}$ imãs permanentes ${ }^{31,32}$ à catálise automotiva. ${ }^{33,34} \mathrm{~A}$ formação do íon trivalente $\left(\mathrm{Ln}^{3+}\right)$ é majoritária para os lantanídeos e esta característica tem forte influência nas aplicações destes. Os átomos dos elementos lantanídeos possuem configuração [Xe $4 \mathrm{f}^{\mathrm{n}} 5 \mathrm{~d}^{1} 6 \mathrm{~s}^{2}(\mathrm{n}=$ 0(La), 1(Ce), 7(Gd) e 14(Lu)) e $[\mathrm{Xe}] 4 \mathrm{f}^{\mathrm{n}} 6 \mathrm{~s}^{2}(\mathrm{n}=3(\mathrm{Pr}), 4(\mathrm{Nd}), 5(\mathrm{Pm})$, 6(Sm), 7(Eu), 9(Tb), 10(Dy), 11(Ho), 12(Er), 13(Tm) e 14(Yb)). Seus íons mais estáveis apresentam-se como $\mathrm{Ln}^{3+}$ e configurações eletrônicas [Xe] $4 \mathrm{f}^{\mathrm{n}}(\mathrm{n}=0-14)$, tendo as orbitais $4 \mathrm{f}$ progressivamente preenchidas do $\mathrm{La}^{3+}\left(4 \mathrm{f}^{0}\right)$ ao $\mathrm{Lu}^{3+}\left(4 \mathrm{f}^{14}\right) \cdot{ }^{24,26,35-37}$ Estas configurações eletrônicas devido repulsão intereletrônica, acoplamento spin-orbita e efeito do ambiente geram termos, níveis e subníveis de energia. $\mathrm{O}$ espaçamento entre os termos é da ordem de $2.10^{4} \mathrm{~cm}^{-1}$, entre os níveis da ordem de $10^{3} \mathrm{~cm}^{-1}$ e entre os subníveis da ordem de $10^{2}$ $\mathrm{cm}^{-1} \cdot 35,38,39$

As orbitais mais internas $4 \mathrm{f}$ e seus elétrons encontram-se protegidos do ambiente químico externo pelas orbitais preenchidas e radialmente mais externas $-5 \mathrm{~s}^{2}$ e $5 \mathrm{p}^{6}$. As configurações $\mathrm{f}^{\mathrm{n}}$, originam grandes números de estados energéticos, por exemplo no caso do $\mathrm{Eu}^{3+}$ (configuração $4 \mathrm{f}^{6}$ ), o número de termos é 119 , de níveis ${ }^{2 \mathrm{~S}+1} \mathrm{~L}_{\mathrm{J}}$ 295 e o de subníveis chega a 3003. Comparando-se com as configurações $\mathrm{d}^{\mathrm{n}}$ o número máximo de subníveis $\left(\mathrm{d}^{5}\right)$ é 252 . Para os termos oriundos dos pares $4 \mathrm{f}^{\mathrm{n}}$ e $4 \mathrm{f}^{14-\mathrm{n}}$, os termos e a ordem de energias são os mesmos, o que se altera é a ordem e os valores das energias dos níveis ${ }^{2 \mathrm{~S}+1} \mathrm{~L}_{\mathrm{J}}$. Os íons lantanídeos se apresentam ao ambiente externo como esferas de carga +3 e pequenas diferenças de raios $\left(\mathrm{La}^{3+}=1,03\right.$ $\AA$ a $\mathrm{Lu}^{3+}=0,86 \AA$ para $\mathrm{NC}=6$ ), não apresentando preferências direcionais em suas ligações. Devido a estas características, ocorre similaridade frente às propriedades químicas e pequeno grau de covalência de suas ligações químicas; já algumas características estruturais são derivadas da contração dos lantanídeos, ${ }^{24,39}$ fenômeno este que consiste na diminuição progressiva dos raios atômicos e iônicos com o aumento do número atômico. A contração dos lantanídeos ocorre fundamentalmente devido à fraca blindagem dos elétrons $4 \mathrm{f}$, resultando em um aumento da carga nuclear efetiva com o aumento do número atômico ${ }^{37,40,41}$

Os lantanídeos, em compostos como as LOFs, atuam como centros coordenantes grandes, uma vez que apresentam elevados raios iônicos, favorecendo números de coordenação altos $(\mathrm{NC}=6$ a 12). Nota-se, ainda, uma tendência a diminuição dos números de coordenação do La ao Lu devido à contração dos lantanídeos. Pearson classificou os íons lantanídeos como ácidos duros e por este motivo, ligantes contendo espécies duras são usualmente empregados ${ }^{37,42}$ A construção de LOFs pode ser facilitada pela escolha de ligantes contendo oxigênio e nitrogênio como pontos coordenantes. As interações entre os íons metálicos e os ligantes ocorrem, neste caso, através de ligações iônicas ou do tipo íon-dipolo. ${ }^{24} \mathrm{~A}$ alta labilidade destes compostos e o baixo grau de covalência das ligações são também atribuídas à baixa interação dos elétrons das orbitais 4 f com o ambiente químico, conforme citado anteriormente, e ao caráter não direcional destas orbitais com relação à geometria. A Tabela 1 exemplifica algumas LOFs, destacando os ligantes e íons empregados, assim como o número de coordenação.

Dentre as propriedades físicas conferidas à materiais e advindas dos lantanídeos, destacam-se as propriedades magnéticas e espectroscópicas. ${ }^{40,50} \mathrm{O}$ forte magnetismo exibido pelos metais e compostos de lantanídeos é originado dos elétrons desemparelhados localizados nas orbitais 4f. Os elétrons desemparelhados possuem momento angular total $(\mathrm{J})$ proveniente da interação entre os momentos orbital (L) e spin (S) resultando em apreciável momento magnético $(\mu)$. Os efeitos magnéticos dos diferentes elétrons não se anulam como em subcamadas completas, tendo como consequência o interessante comportamento magnético dos

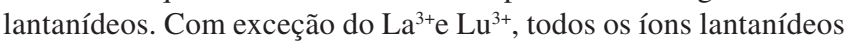
trivalentes contem elétrons desemparelhados e são paramagnéticos. Suas propriedades magnéticas são completamente determinadas pelo estado fundamental (acoplamento spin-órbita ${ }^{2 \mathrm{~S}+1} \mathrm{~L}_{\mathrm{J}}$ ). $\mathrm{O}$ forte acoplamento spin-órbita faz com que o estado fundamental se encontre bem separado do estado excitado. Os estados excitados são termicamente inacessíveis, exceto para $\mathrm{Sm}^{3+}$ e $\mathrm{Eu}^{3+}$, nos quais os estados excitados de menor energia ${ }^{6} \mathrm{H}_{7 / 2} \mathrm{e}^{7} \mathrm{~F}_{1},{ }^{7} \mathrm{~F}_{2}$ respectivamente, contribuem para o momento magnético a temperatura ambiente. ${ }^{37}$ Os momentos magnéticos dos lantanídeos, devido as orbitais 4f, são essencialmente independentes do ambiente, possuindo quase sempre valores próximos ao dos íons livres. Desta forma, não se pode distinguir entre as geometrias de coordenação, como às vezes é possível para os metais de transição, em que as orbitais d são fortemente influenciadas pelo ambiente. Recentemente Fang et al. observaram um pequeno acoplamento ferromagnético entre íons de $\mathrm{Gd}^{3+}$ no composto $\left[\mathrm{Gd}\left(\mathrm{H}_{2} \mathrm{O}\right)(\mathrm{nda})_{1,5}(\text { phen })\right]_{n}($ nda $=2,6$ naftalenodicarboxilato, phen $=$ fenantrolina) à temperatura de $2 \mathrm{~K}^{.1}$

Os íons lantanídeos, com exceção do $\mathrm{La}^{3+}\left(4 \mathrm{f}^{0}\right)$ e $\mathrm{Lu}^{3+}\left(4 \mathrm{f}^{14}\right)$, são luminescentes com emissões características do ultravioleta ao infravermelho próximo. As transições eletrônicas $f$-f ocorrem pela combinação dos mecanismos de dipolo elétrico, dipolo magnético, quadrupolo elétrico e relaxamento vibrônico. ${ }^{52}$ As primeiras são proibidas por paridade e por spin, enquanto o segundo tipo apresenta alguns casos que são permitidos por spin. Evidências experimentais indicam que este fenômeno é proveniente de um mecanismo distinto, atualmente conhecido como dipolo elétrico

Tabela 1. Exemplo de LOFs com os respectivos íons lantanídeos e ligantes empregados

\begin{tabular}{|c|c|c|c|c|}
\hline LOFs & $\mathrm{Ln}^{3+}$ & Ligantes $^{\mathrm{a}}$ & $\mathrm{NC}$ & Referência \\
\hline$\left.\left\{\left[\mathrm{Ln}_{4}\left(\mu_{4}-\mathrm{H}_{2} \mathrm{O}\right)\left(\mathrm{SO}_{4}\right)_{2}(\mathrm{tatb})_{8 / 3}\right)\right] \cdot 3 \mathrm{H}_{2} \mathrm{O} \cdot 10 \mathrm{dmso}\right\}_{n}(\mathrm{PCN}-17)$ & Dy, Er, Yb & $\operatorname{tatb}^{3-}$ & 7 & 43 \\
\hline$\left\{\left[\operatorname{Ln}_{2}\left(4,4^{\prime}-\text { bpy }\right)_{3} \mathrm{Cl}_{6}\right] \cdot 2\left(4,4^{\prime}-\text { bpy }\right)\right\}_{n}$ & $\mathrm{Pr}, \mathrm{Nd}, \mathrm{Sm}, \mathrm{Eu}, \mathrm{Tb}$ & 4,4’-bpy & 7 & 44 \\
\hline$\left\{\left[\operatorname{Ln}_{2}\left(\mathrm{H}_{2} \mathrm{O}\right)_{2}(\mathrm{dmf})_{2}(\mathrm{pam})_{3}\right] \cdot \mathrm{dmf}\right\}_{n}$ & Gd, Dy & pam $^{2-}$ & 8 & 45 \\
\hline$\left\{\left[\mathrm{Eu}_{2}\left(\mathrm{H}_{2} \mathrm{O}\right)_{2}(\mathrm{bdc})_{3} \mathrm{dmf}\right] \cdot \mathrm{H}_{2} \mathrm{O} \cdot \mathrm{dmf}\right\}_{n}$ & $\mathrm{Pr}, \mathrm{Nd}, \mathrm{Sm}, \mathrm{Eu}$ & $\mathrm{bdc}^{2-}$ & 8 & 46 \\
\hline$\left\{\left[\mathrm{Ho}(\mathrm{tz})_{3}(\mathrm{tzH})_{2}\right] \cdot \mathrm{tzH}\right\}_{n}$ & Ho & $\mathrm{tzH}, \mathrm{tz}^{-}$ & 9 & 47 \\
\hline$\left\{\left[\mathrm{Ln}_{2}\left(\mathrm{H}_{2} \mathrm{O}\right)(\mathrm{pda})_{3}\right] \cdot 2 \mathrm{H}_{2} \mathrm{O}\right\}_{n}$ & $\mathrm{Eu}, \mathrm{La}, \mathrm{Er}$ & $\mathrm{pda}^{2-}$ & 9 & 48 \\
\hline$\left\{\left[\mathrm{Eu}_{0,8} \mathrm{~Tb}_{1,2}\left(\mathrm{H}_{2} \mathrm{O}\right)(\mathrm{psa})_{3}\right]\right\}_{n}$ & $\mathrm{Eu}, \mathrm{Tb}$ & $\mathrm{psa}^{2-}$ & 8,9 & 49 \\
\hline
\end{tabular}

${ }^{a}$ tatb $^{3-}=4,4^{\prime}, 4^{\prime \prime}$-triazina-2,4,6-tri-iltribenzoato; 4,4'-bpy= bipiridina; pam $^{2-}=4,4^{\prime}$-metilenobis[3-hidroxi-2-naftalenocarboxilato]; bdc ${ }^{2-}=1,4$-benzenodicarboxilato $; \mathrm{tz}=$ triazolato, $\mathrm{tzH}=1 \mathrm{H}-1,2,4$-triazol; $\mathrm{pda}=1,4$ fenilenodiacetato; $\mathrm{psa}^{2-}=2$-fenilsuccinato. 
forçado - proposto e esclarecido por Judd e Ofelt em 1962; a partir desta teoria as propriedades espectroscópicas dos lantanídeos foram melhor interpretadas. ${ }^{53,54}$ Trabalhos recentes, inclusive de nosso grupo de pesquisa, apresentam diversos estudos das propriedades espectroscópicas dos lantanídeos. ${ }^{24,37,52,55} \mathrm{O}$ processo de emissão ocorre do estado excitado $\mathrm{f}$ de menor energia para um estado $4 \mathrm{f}$ energeticamente menor, podendo ser acompanhado por processos não-radiativos que devem ser evitados (em geral acoplamentos vibracionais) ${ }^{56}$ Como as transições $f$ - $f$ são proibidas por Laporte e por paridade, as emissões apresentam elevado tempo de vida e pequeno coeficiente de absortividade molar $\left(<10 \mathrm{~L} \mathrm{~mol}^{-1} \mathrm{~cm}^{-1}\right)$, resultando em emissões características e cores pálidas. Logo, a excitação direta de íons $\mathrm{Ln}^{3+}$ raramente apresenta forte luminescência ainda que o rendimento quântico seja elevado.

Uma maneira usual de contornar esta situação consiste no acoplamento de espécies que participam em processos de transferência de energia, este processo é conhecido como efeito antena. ${ }^{37,57,58}$ Devido as regras de seleção e, portanto, baixas probabilidades de transição em íons lantanídeos trivalentes, estes limitam sua absorção de luz. No caso das LOFs, recorre-se ao efeito antena a fim de sensibilizar os íons lantanídeos acarretando o aprimoramento de suas emissões. Esta sensibilização envolve processos complexos, os quais encontram-se bem descritos na literatura. ${ }^{49,59,60} \mathrm{Um}$ dos principais mecanismos, representado na Figura 5, ocorre em três etapas. Inicialmente luz é absorvida pelos ligantes orgânicos (permitida por spin) que rodeiam o íon lantanídeo, seguida de cruzamento intersistemas do estado ${ }^{1} \mathrm{~S}$ para o ${ }^{1} \mathrm{~T}$, então a energia é transferida para os estados excitados dos íons lantanídeos ( ${ }^{1} \mathrm{~T} \rightarrow \mathrm{Ln}^{3+}$ ) e, por fim, observa-se a emissão com luminescência característica gerada pelos íons $\mathrm{Ln}^{3+}$. Ligantes orgânicos que possuam forte absorção de fótons são então preferíveis para construção de LOFs luminescentes. As transferências de carga metal-ligante e ligante-metal (TCML e TCLM), e ainda as transições $4 f-5 d$ podem atuar direcionando a energia para o íon lantanídeo. É importante ressaltar que se a transferência de energia do ligante para o metal não for eficiente, podem ser observados, simultaneamente, fluorescência do ligante $\left({ }^{1} \mathrm{~S} \rightarrow{ }^{0} \mathrm{~S}\right)$ e luminescência localizada no íon metálico. A transferência de energia do ligante para o metal suprime a fluorescência e fosforescência do ligante..$^{61,62}$

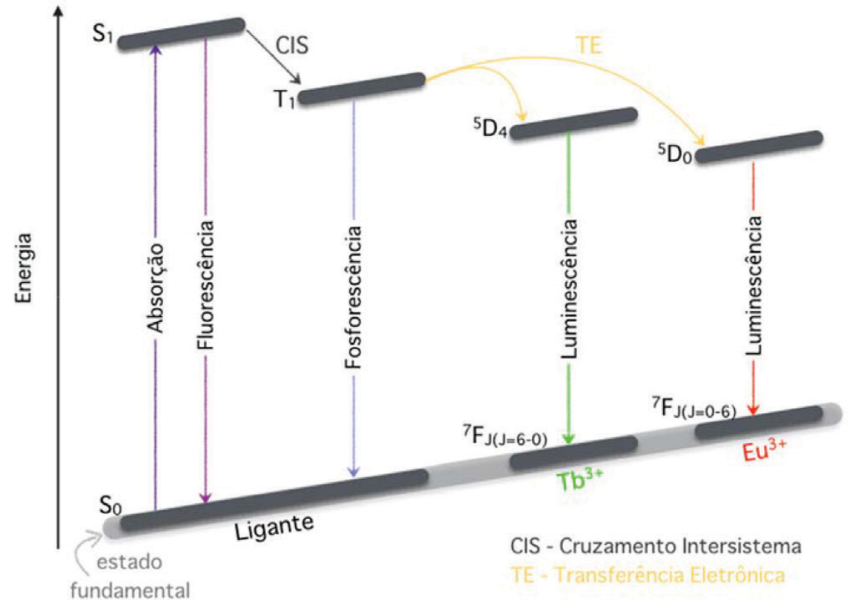

Figura 5. Esquema dos processos de transferência de energia entre as espécies constituintes das LOFs

Considerando as propriedades peculiares dos íons lantanídeos, os próximos tópicos contextualizarão a escolha dos ligantes, sua importância na construção das redes metalorgânicas, tão bem como as rotas de síntese e caracterizações mais usuais e as principais aplicações dos materiais contendo os mesmos.

\section{CONSTRUINDO AS LOFS: LIGANTES ORGÂNICOS MAIS USADOS}

As estruturas das MOFs podem ser descritas e simplificadas como o um arranjo de unidades rígidas primárias: as "esferas" (metal ou agregados destes) e os "bastões" (ligantes). As unidades são conectadas em 1, 2 ou 3 dimensões (Figura 6) conforme citado anteriormente, formando redes que devem, segundo a IUPAC, apresentar apreciável porosidade (redes "abertas") e com habilidade de acomodar moléculas em seu interior. ${ }^{63,64}$ Em contraste com a química supramolecular, as unidades orgânicas e inorgânicas encontram-se covalentemente ligadas, levando à obtenção de estruturas termicamente estáveis até $500{ }^{\circ} \mathrm{C}$ e quimicamente resistentes a muitos solventes.

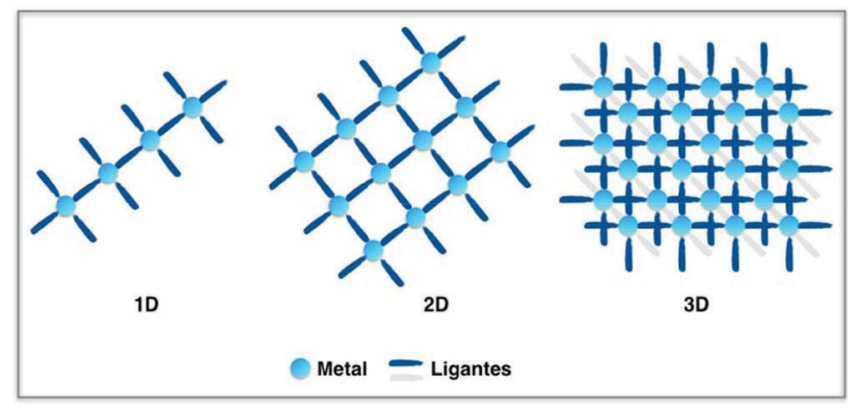

Figura 6. Ilustração da formação de polímeros de coordenação através da conexão do metal ao ligante

Nas LOFs, os íons lantanídeos são coordenados por moléculas orgânicas, as quais podem apresentar variadas cadeias e grupos funcionais, formando uma estrutura supramolecular que pode se repetir em 1, 2 ou 3D. ${ }^{60,65}$ Alguns grupos funcionais simples como carboxilatos, ${ }^{46,66}$ piridinas, ${ }^{67}$ fosfonatos ${ }^{66,67}$ e pirazóis ${ }^{68}$ têm se mostrado eficientes na obtenção de LOFs; ligantes polifuncionais também vêm sendo empregados com sucesso na síntese destas redes. ${ }^{69}$ As estruturas dos ligantes orgânicos mais utilizados na síntese de LOFs podem ser observadas na Figura 7.

As características de comprimento, geometria e grupos funcionais dos ligantes influenciam no tamanho e forma dos poros da rede. Ressalta-se que o grande número de moléculas orgânicas e metais geram um número elevado de combinações, o que acarreta no aumento contínuo do interesse por esses tipos de materiais.

Com intuito de otimizar a previsibilidade das estruturas, alguns autores reportam ainda o conceito de unidades construtoras secundárias (SBUs, exemplificada na Figura 8). ${ }^{70}$ Estas unidades são representações geométricas de clusters ou esferas de coordenação inorgânicas nas quais os modos de coordenação dos ligantes e os ambientes de coordenação dos metais são utilizados na transformação desses fragmentos em redes porosas estendidas utilizando conectores orgânicos politópicos (tipicamente lineares), ${ }^{2}$ como o 1,4 -benzenodicarboxilato entre outros carboxilatos. Ligantes multidentados como os citados anteriormente favorecem a formação de redes mais rígidas devido à possibilidade de agregar íons metálicos em clusters do tipo M-carboxilato (M-O-C). Essas unidades secundárias são consideravelmente mais rígidas pois os íons metálicos estão "fechados" pelos ligantes em suas posições. A partir deste ponto as SBUs servem como vértices largos e rígidos para que outros ligantes orgânicos se liguem com intuito de produzir redes estendidas de elevada estabilidade estrutural. A consideração dos atributos geométricos e químicos das SBUs e dos ligantes leva à predição da topologia da estrutura e, por sua vez, ao desenho e síntese de uma nova classe de materiais com estruturas robustas e alta porosidade..$^{71,72}$ 
<smiles>CC(C)(COC(=O)c1ccc(C(=O)O)cc1)C(=O)O</smiles><smiles>O=C(O)c1ccc(-c2ccc(C(=O)O)cc2)cc1</smiles><smiles>O=C(O)c1cc(C(=O)O)cc(C(=O)O)c1</smiles>

$\mathrm{H}_{3}$ btc<smiles>O=C(O)c1cncc(C(=O)O)c1</smiles>

$\mathrm{H}_{2}$ pdc<smiles>O=C(O)c1ccnc(-c2cc(C(=O)O)ccn2)c1</smiles>

$\mathrm{H}_{2}$ bpy-4,4'-dc<smiles>O=C(O)c1cccc(C(=O)O)n1</smiles>

$\mathrm{H}_{2}$ bda<smiles>O=C(O)c1ccc(-c2cc(-c3ccc(C(=O)O)cc3)cc(-c3ccc(C(=O)O)cc3)c2)cc1</smiles><smiles>O=C(O)c1ccc2cc(C(=O)O)ccc2c1</smiles><smiles>O=C(O)c1ccc(-c2ccc(C(=O)O)cn2)nc1</smiles>

$\mathrm{H}_{2}$ bpy-5,5'-dc

Figura 7. Estrutura de alguns ligantes orgânicos (forma ácida) empregados na síntese de LOFs

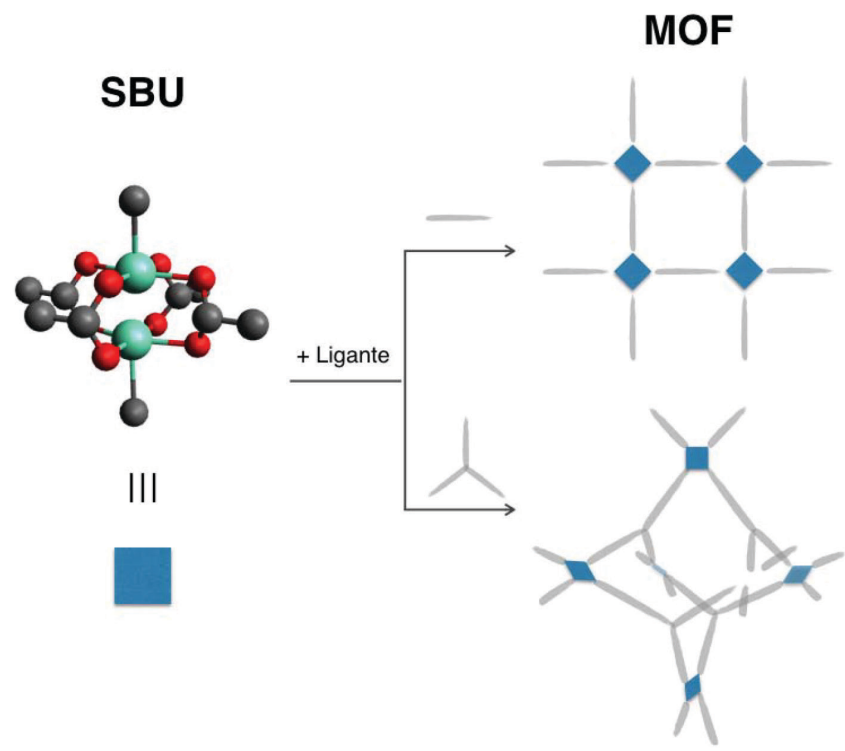

Figura 8. Exemplo de SBUs constituídas por benzenodicarboxilatos coordenados aos centros metálicos. Baseado nas referências 69 e 70

Diferentemente das redes com metais de transição, as LOFs são constituídas por íons lantanídeos que possuem elétrons 4 f tornando-os capazes de ter altos números de coordenação, como citado anteriormente. Além disso, baseado nos conceitos de acidez e basicidade duros e moles (HSAB - Hard and Soft Acid and Bases), ${ }^{24,60}$ os lantanídeos apresentam-se como ácidos mais duros, e em geral, preferem se ligar a doadores duros como $\mathrm{O}$ e $\mathrm{F}$, ao invés de bases moles como ligantes doadores de $\mathrm{P}$ e $\mathrm{S}$. Complexos contendo ligantes com $\mathrm{N}$ como doador são pouco frequentes, devido sua alta basicidade levando em muitos casos à precipitação de hidróxidos. ${ }^{37}$ Além desses fatores, no caso específico das LOFs tais ligantes geram muitas estruturas catiônicas acarretando, em muitos casos, no colapso da estrutura ou perda da porosidade, quando o sistema é submetido a troca de hospedeiros ou baixa pressão. ${ }^{72}$

\section{Os ligantes carboxilatos}

Com base nas propriedades dos íons lantanídeos tão bem como seu comportamento frente a alguns elementos, compreende-se o grande interesse e a busca incessante por novos materiais híbridos e com diferentes modos de coordenação construídos por ligantes carboxilatos e íons $\mathrm{Ln}^{3+}$.55,73,74 Além da grande afinidade dos lantanídeos pelo oxigênio, diferentemente de ligantes neutros do tipo bipiridinas, esses ânions podem balancear a carga catiônica dos metais.

O emprego de carboxilatos multidentados na formação de redes estendidas emergiu, especialmente, diante da dificuldade de ligantes monodentados em permitir uma previsão mais fidedigna da estrutura final devido à flexibilidade da coordenação (monodentada). Uma vez que os carboxilatos possuem múltiplos modos de ligação coordenantes $\mathrm{M}-\mathrm{O}$ que resultam na formação de nós rígidos com geometria fixa, tornam esses clusters $\mathrm{M}-\mathrm{O}$ unidades moleculares construtoras adequadas para a síntese das LOFs. ${ }^{72} \mathrm{O}$ grupo funcional carboxilato pode tanto atuar como um ligante quelante, no qual ambos oxigênios se encontram coordenados ao mesmo metal, como ligar-se a dois centros metálicos. Sendo esta última a habilidade que o torna um importante grupo funcional para a síntese de LOFs com elevada estabilidade térmica. ${ }^{75,76} \mathrm{Com}$ o intuito de obter redes tridimensionais, ligantes contendo um ou mais grupos carboxílicos são usualmente empregados, permitindo assim que os ligantes se conectem em mais de uma dimensão.

Os carboxilatos usados na síntese de LOFs não são restritos à presença de dois grupos na molécula, aqueles contendo três ou quatro grupos também são usuais. Esses ligantes podem ser lineares ou não, apresentar ramificações, ou ainda podem ser rígidos (LR) ou apresentar alguma flexibilidade inerente (LF). ${ }^{77,78} \mathrm{~A}$ variação no número de grupos carboxilatos associada à variação de forma e tamanho favorecem o número elevado de possíveis estruturas para as redes. Os ligantes 
podem ser considerados flexíveis quando apresentam rotação ao redor de uma ligação simples. Desta maneira, apenas ligantes contendo átomos com hibridização $\mathrm{sp}^{3}$ em sua estrutura são ditos flexíveis, ou "semi-rígidos". Por outro lado, ligantes que contenham partes flexíveis, mas que não participam da coordenação M-L como o 2-butil-1,4-benzenodicarboxilato(Bubdc) não devem ser classificados como flexíveis. ${ }^{77}$ Ligantes carboxilatos contendo dois grupos funcionais e que apresentem geometria reta ou curvada como por exemplo o para-bdc ${ }^{2-}$ e o meta-bdc ${ }^{2-}$, podem conter um terceiro grupo como por exemplo no benzeno 1,3,5-tricarboxilato (btc $\mathrm{b}^{3-}$ ) e no 1,3,5-tris(4-carboxifenil) benzoato $\left(b^{3} b^{3-}\right)$ e, então, apresentar uma conformação mais rígida ou ter um pequeno grau de flexibilidade, respectivamente.

Em contraste aos ligantes rígidos, as LOFs baseadas em ligantes flexíveis ainda apresentam dificuldade em sua construção, pois o ligante pode adotar conformações diferentes levando a estruturas com simetrias distintas em cada processo reacional. LOFs contendo ligantes do tipo LF podem tornar-se frágeis e ainda perder sua porosidade após a remoção de moléculas hospedeiras em função da flexibilidade do ligante que sustenta a estrutura da rede. Além disso, essas LOFs mostram-se mais dependentes dos parâmetros de síntese (temperatura, tempo, $\mathrm{pH}$ etc) o que prejudica a previsão da configuração estrutural do material através da rota sintética. ${ }^{77}$ Apesar das desvantagens apontadas, o emprego e desenvolvimento das LOFs construídas com ligantes mais flexíveis favorece a obtenção de novas estruturas cristalinas, com propriedades distintas e inacessíveis a partir de ligantes rígidos. ${ }^{79,80}$ Mais uma vez, enfatiza-se o fator de grande versatilidade das LOFs alterando-se, apenas, os metais e ligantes empregados; ao introduzir os parâmetros reacionais eleva-se ainda mais as possibilidades de novos materiais. Como ligantes de destaque podemos encontrar o bdc ${ }^{2-}$ e seus derivados, sendo as LOFs construídas por dicarboxilatos arílicos baseadas em empilhamentos $\pi-\pi$ e interações de hidrogênio formando estruturas cristalinas diversas e atrativas..$^{43,45,75}$ Apesar de carboxilatos simples como o 1,4 -benzenodicarboxilato formarem, quando coordenados diretamente a íons metálicos, materiais com apreciável porosidade, observa-se a busca intensa pelo aumento do tamanho dos poros, além da variação do tamanho destes com a finalidade de acomodar diversas moléculas nos processos de adsorção. ${ }^{43,81}$ Yaghi et al. ${ }^{2,82}$ em uma de suas mais importantes contribuições para a área de MOFs (também aplicável às LOFs), mostrou como o alongamento do esqueleto dos ligantes, tão bem como o emprego de ligantes contendo substituintes em sua cadeia podem alterar o tamanho de poro da estrutura cristalina desejada, Figura 9. No entanto, é importante ressaltar que a utilização de ligantes com esqueletos relativamente grandes podem levar à formação de estruturas frágeis ou ao aumento da susceptibilidade de interpenetração, do próprio ligante, devido à presença de grandes

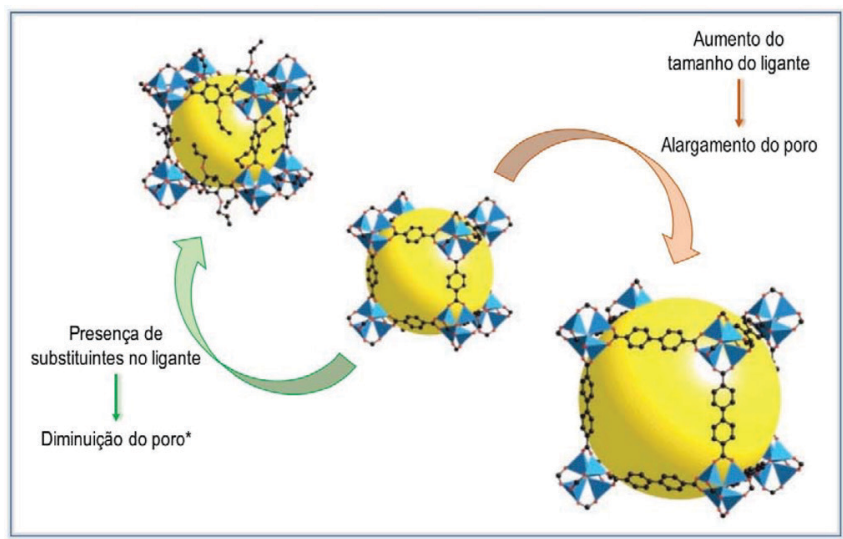

Figura 9. Ilustração do efeito do tamanho elou ramificação dos ligantes no tamanho de poro das MOFs, também aplicável às LOFs. Baseada na referência 82. Reproduzido com permissão da Science espaços vazios. ${ }^{82}$ Uma das maneiras de contornar a situação, baseia-se na diminuição da concentração de reagentes, além disso pode-se recorrer, como citado anteriormente, ao emprego de ligantes tritópicos como por exemplo o btb ${ }^{3-}$.

Ácidos carboxílicos heterocíclicos também se destacam na obtenção de LOFs com diferentes funções. Estes compostos se caracterizam pela presença de pelo menos um elemento diferente do carbono como membro formador do anel, e atuam como ligantes mistos N,O-doadores ao se coordenarem com os íons metálicos, formando portanto redes com topologias específicas. ${ }^{66,73}$ Por exemplo, em trabalho recente Liu et al. destacam o ácido pirazol-3,5-dicarboxílico $\left(\mathrm{H}_{3} \mathrm{pdc}\right)$ como um potencial ligante para a obtenção de redes estendidas com múltiplos sítios de coordenação com geometria assimétrica. Os autores também enfatizam a dependência ácida dos modos de coordenação, no caso do $\mathrm{H}_{3} \mathrm{pdc}$, dentre os três hidrogênios presentes, aquele pertencente ao grupo carboxílico adjacente ao nitrogênio será mais facilmente desprotonado e desta maneira o oxigênio e o nitrogênio adjacentes se coordenam ao metal. Torna-se evidente neste ponto a importância e influência do pH do meio reacional. Ressalta-se ainda a facilidade em remover os hidrogênios ligados a oxigênios de grupos carboxílicos que aquele ligado ao nitrogênio. Esta desprotonação pode afetar os modos de coordenação e, portanto, a estrutura final dos materiais. ${ }^{75}$

Ligantes aromáticos fornecem sistemas (cromóforos) de elétrons $\pi$ deslocalizados aptos a absorver fortemente os fótons de luz e transferi-los para os níveis emissores dos íons lantanídeos. ${ }^{62,83}$ As propriedades luminescentes das LOFs, como já citado, não são estritamente relacionadas aos seus componentes individuais, elas dependem fortemente da estrutura final do polímero de coordenação. E como enfatizado nesta seção, os ligantes desempenham papel fundamental, tanto como unidade construtora quanto como sensibilizadores dos íons lantanídeos, auxiliando na luminescência pelo efeito antena. ${ }^{65,83}$ Dentre as muitas LOFs com aplicações luminescentes, constantemente tem se realizado a busca pelo uso de ligantes semi-rígidos ou mais flexíveis, que apesar da dificuldade previamente relatada em se trabalhar, podem fornecer resultados promissores. Viana et al. utilizaram o ácido 4,4'-sulfonildibenzóico $\left(\mathrm{H}_{2} \mathrm{sda}\right)$ com formato-V, para a síntese de LOFs (do tipo $\left\{\left[\operatorname{Ln}(\mathrm{dmf})_{2}\left(\eta_{2}-\mathrm{NO}_{3}\right)(\mu \text {-sda })\right] \cdot d m f\right\}_{n}$ e outros [Ln= Eu, Dy, Ho, Er, Tm, $\mathrm{Lu}$ com propriedades fotofísicas interessantes (elevado tempo de vida, linhas estreitas e alto grau de pureza das cores). ${ }^{84} \mathrm{Já}$ Wang et al. optaram pelo emprego do ácido 4-(2-carboxifenil)benzeno-1,3-dióico $\left(\mathrm{H}_{3} \mathrm{~L}\right)$ para a construção do $\left\{\left[\mathrm{Ln}\left(\mathrm{H}_{2} \mathrm{O}\right)_{2} \mathrm{~L}\right] \cdot 2 \mathrm{H}_{2} \mathrm{O}\right\}_{n}, \mathrm{Ln}=\mathrm{Tb}$, Eu e Gd. Inicialmente obtiveram LOFs com emissões no vermelho e verde,

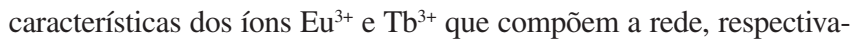
mente, no entanto, a terceira LOF construída com $\mathrm{Gd}^{3+}$ apresentou coloração azul oriunda do ligante. Por fim, os autores obtiveram uma nova série de $\mathrm{LOFs}, \mathrm{Tb}_{1-\mathrm{x}} \mathrm{Eu}_{\mathrm{x}} \mathrm{L}$, pelo ajuste de quantidades desejadas das componentes luminescentes na rede hospedeira de estrutura já bem definida. A luminescência do novo material pode ser ajustada do verde ao vermelho devido à transferência de energia do $\mathrm{Tb}^{3+}$ para o $\mathrm{Eu}^{3+}$ pela alteração da concentração dos íons na rede. ${ }^{85}$

Batista et al. prepararam a LOF $\left[\mathrm{Eu}_{2}\left(\mathrm{H}_{2} \mathrm{O}\right)_{6}(\text { mell })\right]_{n}$ por síntese hidrotermal assistida por micro-ondas, empregaram o ácido benzeno-hexacarboxílico $\left(\mathrm{H}_{6}\right.$ mell), contendo seis carboxilas aptas a coordenar a íons lantanídeos. O composto sintetizado mostrou boa performance na catálise heterogênea de aldeídos para adição de cianeto de trimetilsilano com tempos reacionais curtos, rendimentos apreciáveis, além da possibilidade de reuso do catalisador. ${ }^{86}$

Interessados em obter LOFs com bioatividade, Yan et al. propuseram a construção de uma LOF contendo um fármaco associado ao íon lantanídeo com a intenção de obter potenciais biomateriais com propriedades luminescentes e/ou magnéticas únicas. Assim, os autores descreveram a síntese de LOFs denominadas como $\left\{[\mathrm{Ln}(\mathrm{HL}) \mathrm{L}] \cdot \mathrm{H}_{2} \mathrm{O}\right\}_{n}$ contendo o hidrogeno-acetilsalicilato $\mathrm{HL}^{-}$e o acetilsalicilato $\mathrm{L}^{2-}$ e os 
íons $\mathrm{Tb}^{3+} \mathrm{e} \mathrm{Gd}^{3+}$. Escolheram o ácido salicílico pela sua importância como fármaco e devido à escassez de trabalhos mostrando a formação de complexos entre este ácido e íons lantanídeos, em partes associado a dificuldade reacional. Recentemente conseguiram determinar a estrutura de monocristal da LOF acima descrito, a rede é construída através de ligações entre as hidroxilas fenólicas e o lantanídeo. ${ }^{87}$

Quando o assunto é catálise, a disponibilidade dos poros para que as reações sejam efetivas é de grande importância, no entanto, em muitos casos este fator se torna o ponto crucial e fonte de frustações. O uso de estratégias como a modificação pós-síntese pode ser uma alternativa para contornar esta situação, além de abrir a possibilidade do emprego de diversas LOFs, já existentes, na catálise heterogênea. Muitas LOFs se tornam potenciais catalisadores devido à esfera de coordenação flexível do metal (insaturado em relação à coordenação), além da característica de elevada estabilidade térmica. A modificação pós-síntese pode ser feita pela formação de uma ligação covalente com os ligantes orgânicos ou pela inserção (grafting) de moléculas orgânicas em sítios metálicos. Ren et al. modificaram a LOF de elevada porosidade e boa estabilidade, $\left\{\left[\mathrm{Er}\left(\mathrm{H}_{2} \mathrm{O}\right)(\mathrm{btc})\right] \cdot \mathrm{dmf}_{0,7}\right\}_{n}$ com três diaminas com tamanhos e basicidade diferentes, 1,2-etanodiamina (ed), piperazina (pp) e 1,4-diazobiciclo[2.2.2] octano (dabco) . A LOF modificada com ed exibiu um aumento na estabilidade térmica e porosidade permanente tornando-o um eficiente catalisador heterogêneo em reações de condensação de Knoevenagel. ${ }^{88}$

\section{CARACTERIZAÇÃO}

Para a caracterização das LOFs é importante obter monocristais robustos, que sejam estáveis e com tamanho adequado (geralmente entre 50-250 $\mu \mathrm{m}$ ) para que a análise estrutural por SDRX possa ser realizada. Estes cristais são geralmente obtidos de forma lenta (como por exemplo por processos solvotermais e de evaporação). Atualmente outras técnicas vêm sendo difundidas para produção em escalas multigramas, incluindo abordagens via micro-ondas e em regime de fluxo contínuo. ${ }^{89,90}$

Como as LOFs são materiais cristalinos porosos, sua área superficial, volume e diâmetro de poros pode ser calculada a partir das estruturas cristalinas correspondentes, já existentes na literatura. Walton e Snur ${ }^{91}$ simularam pelo método de Monte Carlo as isotermas de adsorção de nitrogênio em uma série de MOFs estruturalmente conhecidos e mostraram que as áreas superficiais livres concordam bem com as calculadas pelo método Brunauer Emmett Teller (BET). Isto demonstra que as áreas superficiais obtidas utilizando o método BET são fisicamente significativas e passiveis de serem usadas para estruturas tipo frameworks. Sugerem também que comparar a área de superfície livre geometricamente calculada com a área superficial via BET obtida a partir de uma isoterma experimental de adsorção de $\mathrm{N}_{2}$ pode proporcionar uma caracterização útil para amostras que não apresentam estrutura cristalina perfeita. ${ }^{92,93}$ Se a área de superfície BET for inferior à calculada, isto pode ser devido à presença de moléculas de solvente ou de partes colapsadas dos ligantes utilizados dentro da cavidade. A determinação de isotermas de adsorção é a base para a caracterização das propriedades superficiais das MOFs e LOFs..$^{92}$

A cristalografia de raios $\mathrm{X}$ é uma das principais ferramentas de caracterização das LOFs. Através deste método é possível determinar as posições relativas de todos os átomos que constituem a estrutura molecular e a posição relativa de todas as moléculas na célula unitária do cristal. ${ }^{6} \mathrm{~A}$ amostra é constituída por um grande número de cristais, cuja orientação é predominantemente aleatória. O evento de difração é descrito pela lei de Bragg, a qual combina a medida do arranjo regular da estrutura do cristal, chamada de distância entre os planos reticulados, $\mathrm{d}$, o comprimento de onda da radiação de raios $\mathrm{X}, \lambda$, e o ângulo de difração, $\theta$, tal que $n \lambda=2 \mathrm{~d}(\mathrm{hkl}) \operatorname{sen} \theta$. Devido à estrutura periódica das
LOFs, o método de análise estrutural mais usado é a difração de raios $\mathrm{X}$ de monocristal (SXRD). No entanto, uma vez que nem sempre é possível obter cristais com tamanho e qualidade apropriados, a difração de raios X em pó (PXRD) torna-se uma forte aliada, principalmente através do método de Rietvield. ${ }^{94}$ Os padrões de PXRD permitem uma conclusão sobre a reprodutibilidade dos resultados de síntese ou, inversamente, tornam possível explicar diferenças estruturais entre as amostras do mesmo composto preparado por diferentes métodos. ${ }^{95}$ Levando-se em conta os parâmetros de células unitárias das LOFs e a alta densidade eletrônica nos sítios metálicos, torna-se um desafio determinar a estrutura do composto por difração de raios X em pó.

A estabilidade térmica é uma importante característica dos materiais porosos. As LOFs e MOFs, em geral, mostram-se menos resistentes a temperatura se comparadas às zeólitas, visto que sua decomposição ocorre normalmente abaixo de $500{ }^{\circ} \mathrm{C}$. Um método direto para estudar a estabilidade térmica destes compostos baseia-se na análise termogravimétrica (TGA), que relaciona a perda de massa da amostra analisada em função da temperatura. ${ }^{67}$ Quando um equipamento de análise térmica é combinado a um espectrômetro de massa, torna-se possível determinar não apenas a temperatura à qual a massa da amostra é alterada, mas também quais moléculas são responsáveis por esta alteração de massa. O estudo de degradação do material é extremamente importante, visto que se o composto formado for rapidamente decomposto, torna-se difícil sua caracterização por difração de raios $\mathrm{X}$ e, consequentemente, a determinação da estrutura cristalina. A LOF que colapsa após remoção do solvente não pode ser classificada como porosa, pois sua área superficial e a sorção de gases não pode ser determinada. Além disso, muitas aplicações das LOFs, como armazenamento de gases, separação e catálise, dependem de sua estabilidade química. ${ }^{96}$

A estabilidade destes materiais porosos após a remoção de moléculas de solvente é frequentemente avaliada comparando-se os padrões de PXRD após a amostra ser submetida ao aquecimento. Além disso, os dados de difração são comparados aos dados de TGA onde a estabilidade da estrutura é determinada por variações de massa entre a temperatura de perda das moléculas do solvente e a temperatura de colapso da estrutura. A estabilidade térmica das LOFs e o efeito causado por moléculas de solvente dentro das cavidades na estrutura são estudados por difração de raios X em temperatura variável. Alguns trabalhos relatam que a estabilidade térmica das LOFs, estudadas através de TGA e difratometria térmica, é determinada principalmente pelo número e ambiente de coordenação ao invés da topologia da estrutura. ${ }^{97}$

A análise das LOFs a exemplo das MOFs, por espectroscopia vibracional RAMAN e de infravermelho, pode ser extremamente valiosa para detectar presença de impurezas, distorções estruturais e grupos funcionais, podendo ainda oferecer indicações sobre interações entre o centro metálico e os ligantes, bem como as possíveis formas de coordenação. Esta técnica é baseada no fato de que as ligações químicas nas moléculas possuem frequências específicas de vibrações internas. Estas frequências de vibração ocorrem principalmente na região do infravermelho do espectro eletromagnético e são determinadas pela forma da molécula, pelos seus níveis energéticos e pela massa dos átomos que a constituem. ${ }^{98,99}$

Quando há interesse nas propriedades de luminescência, torna-se necessária a análise dos espectros de excitação e emissão bem como dos tempos de vida de estados excitados. A molécula é inicialmente excitada e promovida para um estado eletrônico de maior energia, cujo retorno ao estado fundamental é acompanhado pela emissão de radiação eletromagnética. ${ }^{24,100}$ As LOFs, que normalmente apresentam mistura de diferentes lantanídeos, exibem propriedades espectroscópicas bastantes peculiares. De modo geral, seus espectros de emissão apresentam bandas extremamente estreitas características das transições $4 f-4 f$. 
Alguns aspectos das propriedades luminescentes de lantanídeos como, transições intra-configuracionais, magnitude, número de linhas e as taxas de transições são bastante influenciados pela natureza do ligante. Desta forma os parâmetros de intensidade de Judd-Ofelt podem fornecer valiosas informações a respeito do grau de covalência das ligações químicas entre o íon metálico e os ligantes, a simetria local ao redor do íon lantanídeo e a rigidez do sistema. ${ }^{76,101-103}$ Estes parâmetros têm sido largamente usados no estudo de LOFs contendo íons $\mathrm{Eu}^{3+}$.

Entre as diversas formas de transferências de energia nas LOFs (LMCT, MLCT e transições $5 d-4 f$ ), a sensibilização por luminescência ou "efeito antena" tem sido amplamente exploradas. ${ }^{65}$ Vale ressaltar que, devido à rigidez dos sistemas LOFs, as propriedades luminescentes (tais como intensidade de emissão, tempo de vida e eficiência quântica) podem diferir das propriedades dos complexos.

Como a transferência de energia entre um íon lantanídeo para outro pode influenciar as propriedades luminescentes das LOFs, foi proposto um método para aprimorar o processo de luminescência, alterando as proporções de íons lantanídeos nos compostos. ${ }^{74}$ Devido à transferência de energia dos íons $\mathrm{Tb}^{3+}$ para os íons $\mathrm{Eu}^{3+}$, a intensidade de fluorescência em $540 \mathrm{~nm}$ muda conforme a relação $\mathrm{Tb}^{3+} / \mathrm{Eu}^{3+}$. Outro exemplo que explora a transferência de energia entre estes íons foi ilustrado no estudo da $\operatorname{LOF}\left\{\left[\mathrm{Tb}\left(\mathrm{H}_{2} \mathrm{O}\right)(\mathrm{btc})\right] \cdot 3 \mathrm{H}_{2} \mathrm{O}\right\}_{n} \cdot{ }^{104} \mathrm{~A}$ emissão verde (transição ${ }^{5} \mathrm{D}_{4} \rightarrow{ }^{7} \mathrm{~F}_{5}$ dos íons $\mathrm{Tb}^{3+} 542-546 \mathrm{~nm}$ ), após dopagem do composto com íons $\mathrm{Eu}^{3+}$, foi alterada para amarelo-verde, amarelo, laranja e vermelho-laranja ( transição ${ }^{5} \mathrm{D}_{0} \rightarrow{ }^{7} \mathrm{~F}_{2}$ dos íons $\mathrm{Eu}^{3+}$ - 610-618 nm). Com o aumento da concentração de $\mathrm{Eu}^{3+}$, a intensidade de luminescência do $\mathrm{Tb}^{3+}$ diminui, enquanto que o do $\mathrm{Eu}^{3+}$ aumenta, o que causa a mudança de cor (Figura 10).

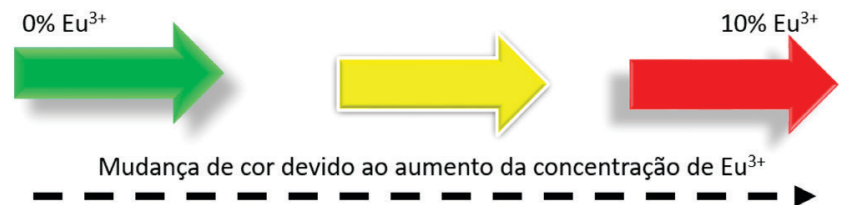

Figura 10. Esquema ilustrativo da mudança de cor que ocorre na LOF $\left\{\left[\mathrm{Tb}\left(\mathrm{H}_{2} \mathrm{O}\right)(b t c)\right] \cdot 3 \mathrm{H}_{2} \mathrm{O}\right\}_{n}: \mathrm{Eu}(0 \%$ á $10 \%)$ devido variação na concentração de Eu ${ }^{3+}$. Excitação em $254 \mathrm{~nm}$. Adaptação da referência 103

Deve-se enfatizar que o uso de um único método é insuficiente para a análise das estruturas de MOFs e LOFs, sendo, portanto, importante utilizar variadas técnicas, como análise elementar (para quantificação de C, N, H, metal, etc.), espectrometria de massas (MS), ressonância magnética nuclear (RMN), etc; em combinação com os métodos descritos acima.

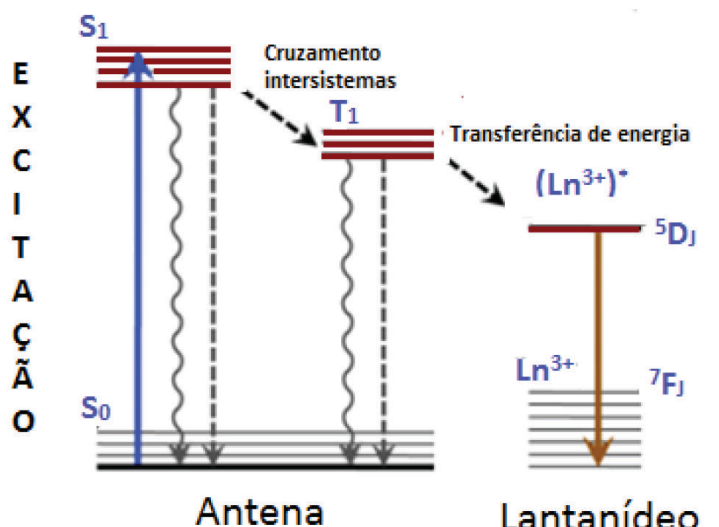

\section{APLICAÇÕES}

Na literatura é possível encontrar inúmeros estudos que relatam sínteses de redes metalorgânicas utilizando as mais diversas metodologias de síntese, metais e ligantes. ${ }^{2,60,105}$ De acordo com a natureza do metal e do ligante, novos materiais são produzidos, podendo ser utilizados em diversas aplicações, Figura 11. As LOFs se beneficiam das características intrínsecas dos íons lantanídeos, tais como propriedades eletrônicas e de coordenação. ${ }^{4} \mathrm{~A}$ posterior funcionalização do material pode ser adquirida selecionando-se cuidadosamente $\mathrm{o}$ ligante a ser usado; refinando-se assim a propriedade final do material. Devido as propriedades das LOFs, como porosidade, magnetismo e luminescência estes materiais possuem grande interesse científico, tecnológico e industrial. ${ }^{106,107}$

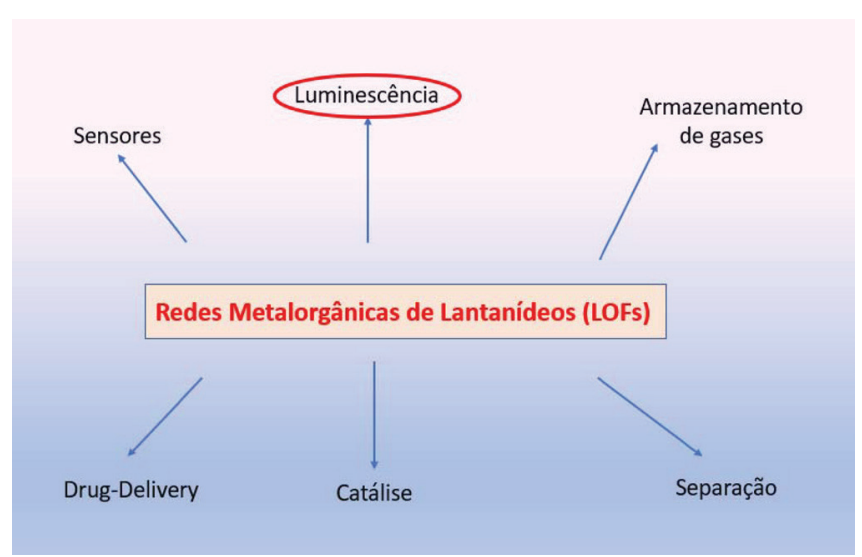

Figura 11. Principais aplicações das LOFs

Comparado aos íons de metais de transição, os íons lantanídeos possuem propriedades eletrônicas, ópticas e magnéticas únicas, possibilitando desta forma um grande desenvolvimento de materiais multifuncionais para aplicações biomédicas, ${ }^{75}$ catálise heterogênea ${ }^{108}$ e sensores químicos. ${ }^{109}$

Os íons lantanídeos são excelentes candidatos para aplicações como em cintilação, luminescência, termometria, sensores e dispositivos óptico-eletrônicos. ${ }^{110-112}$ A luminescência dos lantanídeos origina-se de transições $4 f-4 f$, que por serem proibidas pela regra de Laporte e serem pouco influenciadas pelo ambiente externo, fornecem linhas finas e bem definidas em seus espectros de emissão. Após a coordenação, os ligantes orgânicos podem transferir a energia absorvida pela radiação para os íons lantanídeos (efeito antena), como demonstrado na Figura 12. Este efeito pode resultar em um alto rendimento quântico e/ou maiores tempo de vida.

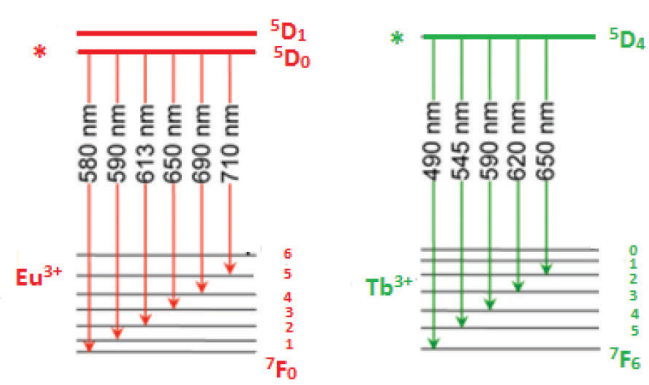

Figura 12. Ilustração do efeito antena e as transições $4 f-4 f$ dos íons E $u^{3+}$ e Tb ${ }^{3+}$ que são comumente observadas por emissões no vermelho e no verde, respectivamente. Adaptação referência 112 
Similar à porosidade, as propriedades ópticas das LOFs podem ser modificadas (aumentadas ou diminuídas) escolhendo-se o centro metálico e o ligante. ${ }^{113}$

Os lantanídeos trivalentes são classificados como ácidos fortes de Lewis e possuem forte atração por átomos de oxigênio (oxofílicos), podendo ser aplicados em diversas reações orgânicas como Diels-Alder e redução de Luche. ${ }^{114} \mathrm{O} \mathrm{Ce}(\mathrm{IV})$ é o único lantanídeo tetravalente, estável em água, com aplicações em reações de oxidação de grupos funcionais como álcool, fenol e éter. Catálises utilizando complexos de lantanídeos têm gerado interesse devido grandes vantagens em reações de formação da ligação assimétrica carbono-carbono. ${ }^{25}$ Estes complexos são muito ativos em reações de substituição de ligantes, especialmente com ligantes duros. Quando ligado a um hetero átomo base de Lewis, o lantanídeo que é um ácido de Lewis retira a densidade eletrônica e desta forma promove a clivagem da ligação heterolítica. ${ }^{115} \mathrm{O}$ elevado grau de labilidade da ligação Ln-ligante, permite uma rápida velocidade de troca nas reações catalíticas.

\section{Catálise}

As LOFs provaram serem úteis em catálise heterogênea, pois combinam vantagens como elevada estabilidade e porosidade, sendo esta última determinada pela escolha dos ligantes. Os poros destas estruturas podem ser sistematicamente adaptados para aplicações catalíticas específicas, como pode ser visualizado na Figura 13. Apesar dos compostos de lantanídeos serem utilizados com frequência como ácidos de Lewis em várias reações, incluindo as catálises assimétricas, ${ }^{116,117}$ a utilização de LOFs em catálise é ainda restrita, no entanto, bastante promissora. LOFs são importantes catalisadores heterogêneos como ácidos de Lewis devido à sua característica única de reatividade e seletividade em condições brandas, como reportado para reações de adição de cianeto em grupos contendo carbonilas para a formação de cianidrinas. ${ }^{93,118}$

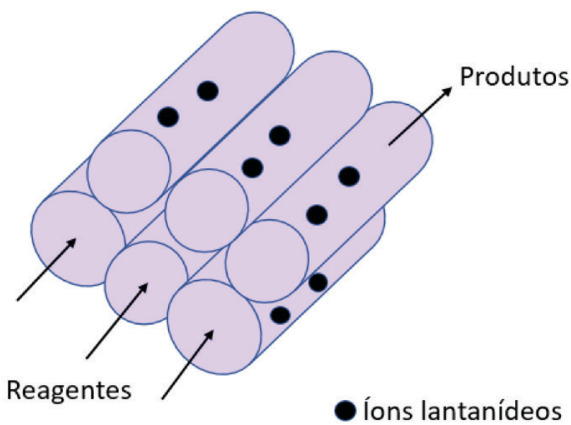

Figura 13. Ilustração dos poros e canais das redes metalorgânicas (LOFs) utilizadas para catálise de materiais orgânicos

Com relação às suas composições químicas e estruturas porosas, as LOFs oferecem diversas vantagens no campo da catálise, tal como fácil difusão de reagentes e produtos através dos poros, controle do ambiente químico e das interações hospede-hospedeiro a partir dos métodos de síntese ou por modificação pós-síntese.
A adição de cianeto à compostos carbonílicos frequentemente da origem à cianidrinas, e consiste num importante método para formação de ligações carbono-carbono ${ }^{119}$ (Esquema 01). É importante notar que as sínteses enantiosseletivas de cianidrinas representam ainda uma via útil para a produção de intermediários orgânicos, tais como ácidos-hidroxil e amino-álcoois quirais. ${ }^{120,121} \mathrm{~A}$ fonte mais comumente usada para fornecer cianeto é o trimetilsililciano (TMSCN). A catálise com TMSCN pode ser induzida termicamente ou por uma enorme gama de catalisadores, incluindo ácidos de Lewis, bases e nucleófilos. Recentemente, Batista et. al. observaram ${ }^{86}$ que as LOFs contendo mell como ligante e os íons $\mathrm{La}^{3+}, \mathrm{Eu}^{3+}, \mathrm{Tb}^{3+} \mathrm{e} \mathrm{Gd}^{3+}$ possuíam atividades catalíticas relevantes. A reação observada indicou que sem a presença do catalisador o rendimento era de apenas $8 \%$, enquanto na presença da LOF apresentavam rápida taxa de conversão com rendimentos superiores a $50 \%$ em temperatura ambiente e até $100 \%$ a $100{ }^{\circ} \mathrm{C}$, em tolueno com solvente. As atividades catalíticas foram estudadas por reações entre benzaldeído e TMSCN em tolueno à temperatura ambiente. Os tempos de reação foram monitorados por cromatografia de filme fino e cromatografia gasosa.

\section{Armazenamento de gases}

Embora as LOFs com tamanhos de poros elevados já tenham sido sintetizadas, a remoção de moléculas de solvente coordenadas à estrutura cristalina ocorre frequentemente acompanhada por um colapso da estrutura. ${ }^{122}$ Os íons lantanídeos caracterizam-se por possuírem alta afinidade por átomos dadores de densidade eletrônica, além do alto número de coordenação. Devido ao estereoimpedimento entre os ligantes orgânicos, torna-se um desafio conseguir que todos os sítios de coordenação dos íons lantanídeos sejam ocupados por estes. Desta forma, as moléculas de solvente, como $\mathrm{H}_{2} \mathrm{O}$, dmf, dmso, etc, se ligam ao íon, completando a esfera de coordenação. Estas moléculas, por sinal, podem ser facilmente removidas resultando na formação de compostos instáveis e de baixa coordenação, causando o colapso total da estrutura. Desta forma, a construção de LOFs com porosidade permanente é um grande desafio para os químicos.

Uma das estratégias para aumentar a porosidade das LOFs baseia-se em escolher ligantes que possuam cadeias com tamanhos maiores. No entanto, os poros formados podem favorecer o processo de interpenetração que estabiliza a estrutura, porém, limita o tamanho dos poros na estrutura cristalina, influenciando drasticamente a adsorção de gases, Figura 14. Uma forma de evitar este problema baseia-se na utilização de ligantes orgânicos que possuam alto estereoimpedimento, evitando assim a interpenetração das redes, embora esta escolha leve à possibilidade de redução dos tamanhos dos poros. Outra opção é a utilização de unidades de construção secundária em forma de haste geradas in $\operatorname{situ}^{123}$ (SBUs). A rigidez das SBUs neste formato evita efetivamente a interpenetração, melhorando assim a porosidade das estruturas. Utilizando como ligante a molécula de fenantrolina, que possui alto estereoimpedimento, $\mathrm{He}$ et.al. ${ }^{124}$ observaram que as LOFs formadas possuíam porosidade permanente, que foi comprovado por testes de adsorção de gases. As espécies hospedeiras que se encontram dentro dos poros podem ser neutras, catiônicas ou aniônicas, como $\mathrm{H}_{2} \mathrm{O}$, dma (dimetilamônio) ou<smiles>[X]C(=O)C=O</smiles>
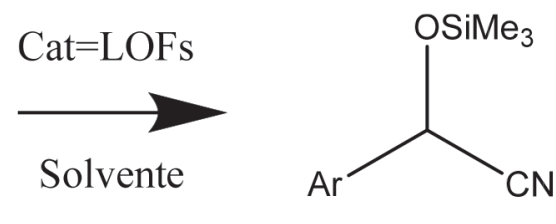

Esquema 1. Representação da reação de adição de cianeto em grupos contendo carbonila para formação de cianidrinas 
$\mathrm{NO}_{3}{ }^{-}$, respectivamente. Caso a espécie contenha carga, o poro torna-se inacessível, visto que a compensação de carga é obrigatória para que o sistema não se colapse. a)

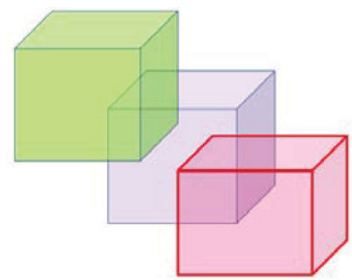

b)

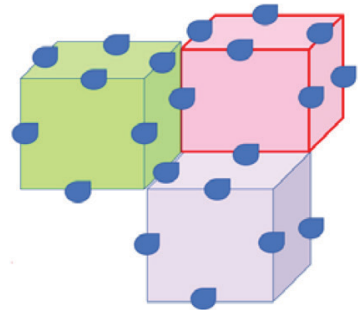

Ligantes orgânicos com alto estereoimpedimento
Figura 14. (a) Representação esquemática de redes interpenetradas sem canais, (b) Redes porosas não interpenetradas construídas a partir de ligantes com alto estereoimpedimento

\section{Luminescência}

A luminescência é uma das principais características das LOFs se comparadas às MOFs contendo metais de transição. Com exceção dos íons $\mathrm{La}^{3+}$ e $\mathrm{Lu}^{3+}$, todos os íons $\mathrm{Ln}^{3+}$ são luminescentes e suas linhas de emissão $f-f$ cobrem desde o UV $\left(\mathrm{Ce}^{3+}, \mathrm{Gd}^{3+}\right)$, VIS $\left(\mathrm{Pr}^{3+}\right.$, $\left.\mathrm{Sm}^{3+}, \mathrm{Eu}^{3+}, \mathrm{Tb}^{3+}, \mathrm{Dy}^{3+}, \mathrm{Tm}^{3+}\right)$ e NIR $\left(\mathrm{Pr}^{3+}, \mathrm{Nd}^{3+}, \mathrm{Ho}^{3+}, \mathrm{Er}^{3+}, \mathrm{Yb}^{3+}\right)$. Os lantanídeos apresentam transições eletrônicas principalmente de dois tipos: a) por dipolo elétrico as quais obedecem as regras de seleção a seguir: $\Delta \mathrm{S}=0 ; \Delta \mathrm{L} \leq 6 ; \Delta \mathrm{J} \leq 6 ;|\Delta \mathrm{J}|=2,4,6$ quando $\mathrm{J}$ ou $\mathrm{J}^{*}=0$. As regras para $\mathrm{L}$ e $\mathrm{S}$ são violadas devido às combinações dos estados Russel-Saunders, assim a transição ${ }^{5} \mathrm{D}_{2} \rightarrow{ }^{7} \mathrm{~F}_{0}$ é permitida pois o estado ${ }^{5} \mathrm{D}_{2}$ é na realidade uma combinação linear de ${ }^{5} \mathrm{D}_{2},{ }^{7} \mathrm{~F}_{2}$, etc. As regras de seleção para $\mathbf{J}$ são mais rígidas e podem ser violadas por "J-mixing", o que na realidade leva a um efeito muito mais fraco. A transição ${ }^{5} \mathrm{D}_{0} \rightarrow{ }^{7} \mathrm{~F}_{0}$, no entanto, pode apresentar banda intensa em alguns compostos quando determinados valores para os parâmetros do campo cristalino são presentes. Temos ainda como consequência da regra de Laporte que as transições $f \rightarrow f$ são proibidas por dipolo elétrico (representações de simetria do dipolo elétrico do tipo $\Gamma \mathrm{u}$ ) em compostos com centro de inversão ocorrendo, no entanto, por mecanismo de acoplamento vibrônico. b) por dipolo magnético obedecendo as seguintes regras de seleção: $\Delta \mathrm{S}=0, \Delta \mathrm{L}=0, \Delta \mathrm{J}=0$, \pm 1 (exceto para $\mathrm{J}=0 \rightarrow \mathrm{J}=0$, que é proibida). As transições por dipolo magnético são em geral muito mais fracas, aparecendo, entretanto, no caso do $\mathrm{Eu}^{3+}$, bandas com maior intensidade (ex. ${ }^{5} \mathrm{D}_{0} \rightarrow{ }^{7} \mathrm{~F}_{1}$ ), mesmo assim menos intensas que as de dipolo elétrico. Estas transições são permitidas em ambientes com centro de inversão pois as representações de simetria para o dipolo magnético são do tipo $\Gamma$ g. ${ }^{125}$ Estas considerações fazem com que os termos fluorescência e fosforescência não sejam adequados para as emissões de lantanídeos devendo ser usado o termo luminescência ou ainda fotoluminescência. As linhas de emissão $f$ - $f$ são finas devido à baixa influência do campo cristalino, que faz com que a configuração dos elétrons no estado excitado não perturbe o padrão das ligações nas moléculas, uma vez que as orbitais $4 \mathrm{f}$ não participam (ou pouco participam) efetivamente da ligação. ${ }^{22,52,126}$ Portanto, as distâncias internucleares permanecem quase iguais no estado excitado, o que gera bandas estreitas e um pequeno deslocamento "Stokes". Uma situação diferente é encontrada em moléculas orgânicas nas quais a excitação promove um alongamento das ligações químicas, resultando em grandes deslocamentos "Stokes" e bandas largas de emissão. Devido à grande diversidade das LOFs, que são sistemas complexos incluindo variados tipos de ligantes, íons metálicos ou clusters e íons ou moléculas hospedeiras, a fotoluminescência pode ocorrer devido vários mecanismos.
Os materiais luminescentes têm sido amplamente explorados e usados em aplicações como displays, sensores, dispositivos óticos, OLEDs, etc, devido às emissões finas com alta pureza de cor. ${ }^{127} \mathrm{~A}$ luminescência em LOFs pode ser originada por transições $4 f-4 f, 4 f-5 d$, transferência de carga metal-ligante ou ligante-metal, transferência através de estados excitados do ligante (efeito antena). ${ }^{128}$

Para aumentar a eficiência de luminescência são comumente utilizados ligantes que atuam como antenas (ou sensibilizadores), transferindo energia diretamente para os íons lantanídeos. Ao longo dos últimos anos, foram feitos esforços para aumentar os coeficientes de absorção e assim obter emissões significativamente mais intensas. ${ }^{129}$

$\mathrm{O}$ íon $\mathrm{Eu}^{3+}$ é bem conhecido por sua luminescência na região do vermelho no espectro e possui grande vantagem com relação aos outros íons $\mathrm{Ln}^{3+}$ visto que o seu estado fundamental ${ }^{7} \mathrm{~F}_{0}$ é não degenerado $(\mathrm{J}=0)$, o que favorece o estudo das propriedades espectroscópicas. ${ }^{130,131}$ $\mathrm{O}$ número de linhas observados na transição ${ }^{5} \mathrm{D}_{0} \rightarrow{ }^{7} \mathrm{~F}_{\mathrm{J}}$ (Figura 15) nos espectros de luminescência permite determinar o sítio de simetria do íon $\mathrm{Eu}^{3+}{ }^{55} \mathrm{~A}$ ausência ou a presença de uma única banda para transição ${ }^{5} \mathrm{D}_{0} \rightarrow{ }^{7} \mathrm{~F}_{0}$, observada no espectro de luminescência, indica fortemente que todos os íons $\mathrm{Eu}^{3+}$ experimentam o mesmo efeito de campo cristalino e que ocupam sítios de mesma simetria. ${ }^{35,55}$ A relação entre as intensidades da transição por dipolo magnético $\left({ }^{5} \mathrm{D}_{0} \rightarrow{ }^{7} \mathrm{~F}_{1}\right)$ e a transição por dipolo elétrico $\left({ }^{5} \mathrm{D}_{0} \rightarrow{ }^{7} \mathrm{~F}_{2}\right)$ traz informação sobre o ambiente de simetria.

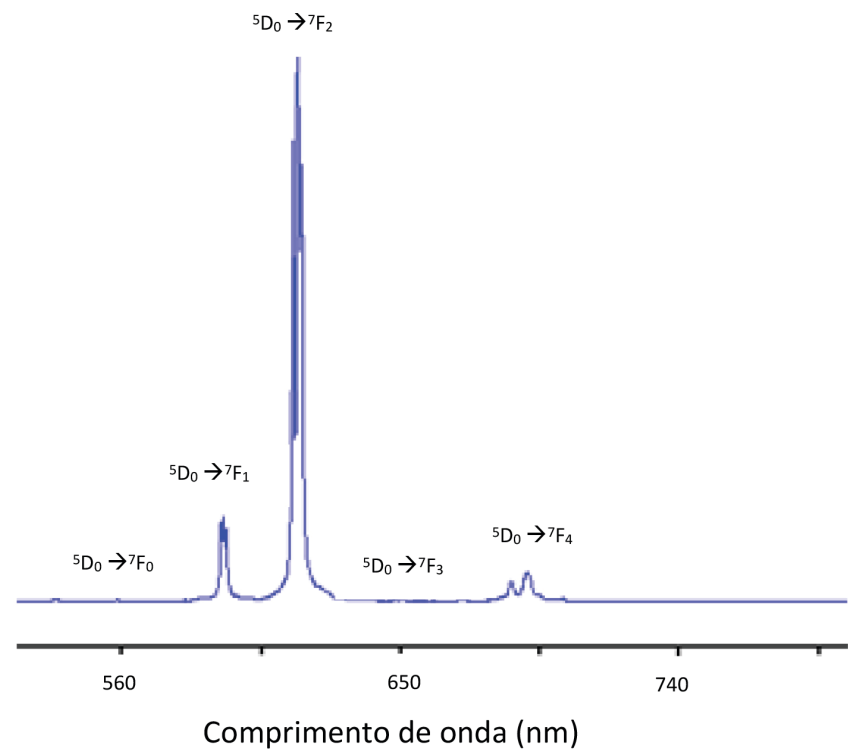

Figura 15. Representação do espectro de emissão $\left(\lambda_{\text {exc. }}=394 \mathrm{~nm}\right)$ do íon $\mathrm{Eu}^{3+}$ para a LOF $\left\{\text { dma }\left[\mathrm{Eu}\left(\mathrm{H}_{2} \mathrm{O}\right)(\mathrm{ox})_{2}\right]\right\}_{n} \cdot 3 \mathrm{H}_{2} \mathrm{O}$

É possível escolher ligantes que sirvam como "antenas", transferindo energia para o íon lantanídeo, a fim de se aumentar a luminescência do sistema. Um exemplo é o ligante bidentado 2,5-tiofenodicarboxilato $\left(\operatorname{tdc}^{2-}\right)$, o qual pertence à classe de heterocíclicos, que pode estabelecer ligações (pontes) entre diferentes centros metálicos e adotar variados modos de coordenação, produzindo redes multidimensionais, incluindo estruturas bidimensionais (2D) e tridimensionais (3D). De acordo com o estudo de fotoluminescência, a ausência da banda de fosforescência do ligante nos espectros indica que a transferência de energia do ligante para o metal foi eficiente..$^{55}$

As propriedades luminescentes das LOFs foram utilizadas como marcadores na identificação de resíduos conhecidos como " gun shot residue" (GSR). ${ }^{132}$ Os resíduos de descarga de arma de fogo são partículas microscópicas, que ficam depositadas nas mãos e roupas do atirador, resultantes das reações de condensação a altas pressões que 
ocorrem durante o processo de disparo. São formados principalmente de partículas queimadas e não queimadas do propulsor - e possíveis fragmentos da bala, da caixa do cartucho e da arma de fogo. O GSR é usado para estimar a distância em que uma bala é disparada, reconhecer a procedência da bala, além de fornecer informações importantes para identificar suspeitos. ${ }^{133}$ Desta forma torna-se necessário encontrar metodologias que favoreçam a investigação forense. Uma importante característica das LOFs é a estabilidade térmica, sendo resistentes à altas temperaturas e quimicamente estáveis após longos períodos de tempo, tornando-as candidatos ideais para marcadores fotoluminescentes. Além disso, é importante que os materiais sejam inertes, devido ao contato com a pólvora. Uma das estruturas sintetizadas para tal estudo foi a $[\mathrm{Eu}(\mathrm{dpa})(\mathrm{Hdpa})]_{n}$, sendo dpa= piridina-2,6-dicarboxilato e Hdpa= hidrogenopiridinadicarboxilato, que possui estrutura bidimensional (2D), que apresentou alta fotoluminescência e suas propriedades ópticas permaneceram inalteradas após o disparo da bala. O GSR marcado foi identificado visualmente na mão e na roupa do atirador, na arma e na superfície alvo, além disso, evidenciou-se que as amostras coletadas permaneceram luminescentes por mais de 30 meses. Os espectros de emissão da LOF adquiridos à temperatura ambiente a partir da excitação do ligante mostraram a típica emissão no vermelho associada a transição ${ }^{5} \mathrm{D}_{0} \rightarrow{ }^{7} \mathrm{~F}_{2}$. Após os tiros, verificou-se que as transições características do íon $\mathrm{Eu}^{3+}$ permaneceram semelhantes às dos marcadores puros, sugerindo que as estruturas dos marcadores não tinham sofrido alterações significativas. ${ }^{129}$

\section{PERSPECTIVAS}

As MOFs vêm se mostrando altamente promissoras em um grande número de aplicações, incluindo aquelas destacadas no item anterior. O interesse pelas redes híbridas e porosas segue crescente e não seria diferente para as MOFs contendo lantanídeos - as LOFs. Apesar dos excelentes resultados obtidos até o momento, como exemplificado ao longo do texto, o desenvolvimento e aprimoramento das LOFs se mantém como foco de estudo na comunidade científica.

As interações entre os ligantes e os centros metálicos favorecem o controle da estrutura tridimensional desejada, do tamanho de poro do material, além de suas propriedades químicas, tornando as MOFs altamente atrativas. Não obstante, os lantanídios são conhecidos por suas propriedades espectroscópicas, magnéticas e de oxirredução únicas. Quando comparados a outros metais, destacam-se os grandes momentos magnéticos, o forte acoplamento spin-órbita e os elevados números de coordenação que podem ser alcançados.

Sem dúvida, grande parte dos esforços envolvidos no desenvolvimento de MOFs concentram-se nas propriedades que resultam da porosidade destes materiais, as quais vão desde aplicações clássicas como o armazenamento de gases até a possibilidade de emprega-los em drug delivery, ${ }^{134,135}$ devido à superfície interna ser adaptável. Além destas, para as LOFs as aplicações envolvendo suas propriedades luminescentes são as que mais se destacam, especialmente no sensoriamento de metais e emissão de luz. ${ }^{26,49}$

Tem-se observado crescimento no interesse pelo desenvolvimento de LOFs nanoestruturadas, seja considerando o tamanho dos poros ou das partículas que constituem os materiais. Em muitas áreas as dimensões em nanoescala são necessárias, as nano-LOFs exibem a combinação da rica diversidade de composições, estruturas e propriedades de granulometria das LOFs com as vantagens óbvias dos nanomateriais. ${ }^{81,104} \mathrm{~A}$ excelente dispersabilidade dos materiais em nanoescala permite que estes interajam diretamente com outras espécies químicas e não necessitem serem ativados, o que pode acarretar numa melhor aplicabilidade das LOFs em sistemas biológicos, por exemplo. Um dos principais desafios para melhorar o desempenho em aplicações práticas de LOFs nanoestruturadas é diminuir o tamanho e morfologia das partículas, além de mantê-las homogêneas e monodispersas. Íons $\mathrm{Ln}^{3+}$, ou nanopartículas de materiais que os contém, podem ser adicionadas a redes metalorgânicas já conhecidas, com o intuito de aprimorar o seu desempenho. ${ }^{136}$ As características excepcionais das MOFs permitiram aos pesquisadores explorar a combinação destas com outros materiais funcionais para formar novos compósitos com propriedades avançadas. Nanopartículas metálicas, polímeros e biomoléculas podem ser combinadas com LOFs para fornecer novos materiais de alto desempenho nas mais diversas áreas. Os compósitos são os mais estudados destes sistemas e baseiam-se na integração de metal e nanopartículas de óxidos metálicos com MOFs/LOFs. Isto pode ser atribuído à versatilidade das abordagens sintéticas para óxido metálicos (cerâmica) e materiais metálicos. ${ }^{137,138}$

A busca por materiais multifuncionais tornou-se requisito para as principais aplicações que influenciam nossas vidas diárias, se tornando não só foco dos pesquisadores como também das indústrias. Produzir MOFs e LOFs em grande escala é de grande interesse para as indústrias químicas, portanto, segue como um dos principais desafios nesta área.

As LOFs têm enorme diversidade estrutural e química, podendo ser moldadas para diversas aplicações, tornando-as materiais muito atraentes para a preparação de compósitos com propriedades otimizadas e especificas. Em particular, a versatilidade de MOFs em combinação com as propriedades fotofísicas e fotoquímicas excepcionais dos íons lantanídeos resultam nas LOFs, materiais de destaque. Esta revisão buscou trazer um pouco das propriedades químicas e aplicações das LOFs, além de mostrar o estado da arte, o rápido desenvolvimento e a importância das redes metalorgânicas contendo lantanídeos como uma classe de materiais multifuncionais.

\section{AGRADECIMENTOS}

Ao CNPq e à FAPESP pelos auxílios recebidos e ao Prof. R. B Faria pelas valiosas sugestões.

\section{REFERÊNCIAS}

1. Robin, A. Y.; Fromm, K. M.; Coord. Chem. Rev. 2006, 250, 2127.

2. Rowsell, J. L. C.; Yaghi, O. M.; Microporous Mesoporous Mater. 2004, 73,3 .

3. Tomic, E.; J. Appl. Polym. Sci. 1965, 9, 3745.

4. Biondi, C.; Bonamico, M.; Torelli, L.; Vaciago, A.; Chem. Commun. 1965, 10, 191.

5. Yaghi, O. M.; Li, H.; J. Am. Chem. Soc. 1995, 117, 10401.

6. Li, J.-R.; Kuppler, R. J.; Zhou, H.-C.; Chem. Soc. Rev. 2009, 38, 1477.

7. Chavan, S.; Vitillo, J. G.; Groppo, E.; Bonino, F.; Lamberti, C.; Dietzel, P. D. C.; Bordiga, S.; J. Phys. Chem. C 2009, 113, 3292.

8. Horcajada, P.; Chalati, T.; Serre, C.; Gillet, B.; Sebrie, C.; Baati, T.; Eubank, J. F.; Heurtaux, D.; Clayette, P.; Kreuz, C.; Chang, J.-S.; Hwang, Y. K.; Marsaud, V.; Bories, P.-N.; Cynober, L.; Gil, S.; Férey, G.; Couvreur, P.; Gref, R.; Nat. Mater. 2010, 9, 172.

9. Frem, R. C. G.; Arroyos, G.; Lucena, G. N.; da Silva Flor, J. B.; Fávaro, M. A.; Coura, M. F.; Alves, R. C. In Recent Advances in Complex Functional Materials; Longo, E., La Porta, F. de A., eds.; Springer International Publishing: Cham, 2017; pp. 339-369.

10. Cook, T. R.; Zheng, Y.-R.; Stang, P. J.; Chem. Rev. 2013, 113, 734.

11. Young, D. M.; Geiser, U.; Schultz, A. J.; Wang, H. H.; J. Am. Chem. Soc. 1998, 120, 1331.

12. Paz, F. A. A.; Klinowski, J.; Inorg. Chem. 2004, 43, 3882.

13. Li, J.; Bu, X.; Zhang, R.; Dalton Trans. 2004, 813.

14. Zou, R. Q.; Li, J. R.; Xie, Y. B.; Zhang, R. H.; Bu, X. H.; Cryst. Growth Des. 2004, 4, 79. 
15. Forster, P. M.; Burbank, A. R.; Livage, C.; Férey, G.; Cheetham, A. K.; Chem. Commun. 2004, 368.

16. Tynan, E.; Jensen, P.; Kruger, P. E.; Lees, A. C.; Chem. Commun. 2004, 776.

17. Kepert, C. J.; Rosseinsky, M. J.; Chem. Commun. 1999, 536, 375.

18. Kim, J.; Chen, B.; Reineke, T. M.; Li, H.; Eddaoudi, M.; Moler, D. B.; O'Keeffe, M.; Yaghi, O. M.; J. Am. Chem. Soc. 2001, 123, 8239.

19. Reineke, T. M.; Eddaoudi, M.; Fehr, M.; Kelley, D.; Yaghi, O. M.; J. Am. Chem. Soc. 1999, 121, 1651.

20. Rosi, N. L.; Eddaoudi, M.; Kim, J.; O’Keeffe, M.; Yaghi, O. M.; CrystEngComm 2002, 4, 401.

21. Reineke, T. M.; Eddaoudi, M.; O’Keeffe, M.; Yaghi, O. M. ;Angew. Chem., Int. Ed. 1999, 38, 2590.

22. Serra, O. A.; J. Braz. Chem. Soc. 2011, 22, 811.

23. Gonçalves e Silva, F. R.; Capelo, R. G.; Albuquerque, R. Q.; J. Lumin. 2016, 170, 472.

24. Sousa Filho, P. C. de; Lima, J. F.; Serra, O. A.; J. Braz. Chem. Soc. 2015 , 26, 2471.

25. Pagis, C.; Ferbinteanu, M.; Rothenberg, G.; Tanase, S.; ACS Catal. 2016, 6, 6063.

26. Cui, Y.; Chen, B.; Qian, G.; Coord. Chem. Rev. 2014, 273-274, 76.

27. Fordham, S.; Wang, X.; Bosch, M.; Zhou, H.-C. In Lanthanide MetalOrganic Frameworks; Cheng, P., ed.; Springer: Berlin, 2014; pp. 1-27.

28. Yao, Q.; Bermejo Gómez, A.; Su, J.; Pascanu, V.; Yun, Y.; Zheng, H.; Chen, H.; Liu, L.; Abdelhamid, H. N.; Martín-Matute, B.; Zou, X.; Chem. Mater. 2015, 27, 5332.

29. de Oliveira, T. C.; Santos, H. P.; Lahoud, M. G.; Franco, D. F.; Freire, R. O.; Dutra, J. D. L.; Cuin, A.; de Lima, J. F.; Marques, L. F.; J. Lumin. 2017, 181, 196.

30. de Sousa Filho, P. C.; Serra, O. A.; J. Lumin. 2009, 129, 1664.

31. Pathak, A. K.; Gschneidner, K. A.; Khan, M.; McCallum, R. W.; Pecharsky, V. K.; J. Alloys Compd. 2016, 668, 80.

32. Smith Stegen, K.; Energy Policy 2015, 79, 1.

33. Nascimento, L. F.; Lima, J. F.; de Sousa Filho, P. C.; Serra, O. A.; Chem. Eng. J. 2016, 290, 454.

34. Shinjoh, H.; J. Alloys Compd. 2006, 408-412, 1061.

35. Bunzli, J.-C. G. In Lanthanide probes in life, chemical and earth sciences; Jean- Bünzli, C. G., Choppin, G. R., eds.; Elsevier: New York, 1989; pp. 219-293.

36. Sousa Filho, P. C. de; Serra, O. A.; Quim. Nova 2014, 37, 753.

37. Cotton, S.; Lanthanide and Actinide Chemistry; John Wiley \& Sons, Ltd: Chichester, UK, 2006.

38. Xue, D.; Zuo, S.; Ratajczak, H.; Phys. B 2004, 352, 99.

39. Binnemans, K.; Görller-Walrand, C.; Chem. Phys. Lett. 1995, 235, 163.

40. Bünzli, J.-C. G.; André, N.; Elhabiri, M.; Muller, G.; Piguet, C.; J. Alloys Compd. 2000, 303-304, 66.

41. Cahill, C. L.; de Lill, D. T.; Frisch, M.; CrystEngComm 2007, 9, 15.

42. Pearson, R. G.; J. Am. Chem. Soc. 1963, 85, 3533.

43. Ma, S.; Yuan, D.; Wang, X.; Zhou, H.; Inorg. Chem. 2009, 48, 2072.

44. Höller, C. J.; Mai, M.; Feldmann, C.; Müller-Buschbaum, K.; Dalton Trans. 2010, 39, 461.

45. Biswas, S.; Jena, H. S.; Goswami, S.; Sanda, S.; Konar, S.; Cryst. Growth Des. 2014, 14, 1287.

46. Decadt, R.; Van Hecke, K.; Depla, D.; Leus, K.; Weinberger, D.; Van Driessche, I.; Van Der Voort, P.; Van Deun, R.; Inorg. Chem. 2012, 51, 11623.

47. Müller-Buschbaum, K.; Mokaddem, Y.; Höller, C. J.; Z. Anorg. Allg. Chem. 2008, 634, 2973.

48. Ren, Y.; Liang, J.; Lu, J.; Cai, B.; Shi, D.; Qi, C.; Jiang, H.; Chen, J.; Zheng, D.; Eur. J. Inorg. Chem. 2011, 2011, 4369.

49. Gomez, G. E.; Kaczmarek, A. M.; Deun, R. Van; Brusau, E. V; Narda, G. E.; Vega, D.; Iglesias, M.; Gutierrez-puebla, E.; Monge, M. Á.; Eur. J. Inorg. Chem. 2016, 1577.
50. Li, B.; Wen, H.-M.; Cui, Y.; Qian, G.; Chen, B.; Prog. Polym. Sci. 2015, $48,40$.

51. Fang, M.; Li, X.; Cui, P.; Zhao, B.; J. Solid State Chem. 2015, 223, 138.

52. Bünzli, J.-C. G.; Eliseeva, S. V In Lanthanide Luminescence: Photophysical, Analytical and Biological Aspects; Hänninen, P., Härmä, H., eds.; Springer, 2010; pp. 1-45.

53. Judd, B. R.; Phys. Rev. 1962, 127, 750.

54. Ofelt, G. S.; J. Chem. Phys. 1962, 37, 511.

55. Marques, L. F.; Cantaruti Júnior, A. A. B.; Ribeiro, S. J. L.; Scaldini, F. M.; Machado, F. C.; Opt. Mater. 2013, 35, 2357.

56. Bünzli, J.-C. G.; Eliseeva, S. V.; J. Rare Earths 2010, 28, 824.

57. Bünzli, J.-C. G.; André, N.; Elhabiri, M.; Muller, G.; Piguet, C.; J. Alloys Compd. 2000, 303-304, 66

58. Valeur, B.; Bardez, E.; Lehn, J.-M.; Jullien, L.; Canceill, J.; Angew. Chem., Int. Ed. Engl. 1995, 33, 2438.

59. Marques, L. F.; Corrêa, C. C.; da Silva, R. R.; dos Santos, M. V.; Ribeiro, S. J. L.; Machado, F. C.; Inorg. Chem. Commun. 2013, 37, 66.

60. Bünzli, J.-C. G.; J. Coord. Chem. 2014, 67, 3706.

61. Meyer, L. V.; Schönfeld, F.; Müller-Buschbaum, K.; Chem. Commun. 2014, 50, 8093.

62. Xu, H.; Cao, C.-S.; Kang, X.-M.; Zhao, B.; Dalton Trans. 2016, 45, 18003.

63. Batten, S. R.; Champness, N. R.; Chen, X.-M.; Garcia-Martinez, J.; Kitagawa, S.; Öhrström, L.; O’Keeffe, M.; Suh, M. P.; Reedijk, J.; CrystEngComm 2012, 14, 3001.

64. Öhrström, L.; ChemViews 2013.

65. Rocha, J.; Carlos, L. D.; Paz, F. a A.; Ananias, D.; Chem. Soc. Rev. 2011, 40, 926.

66. Allendorf, M. D.; Stavila, V.; CrystEngComm 2015, 17, 229.

67. Howarth, A. J.; Liu, Y.; Li, P.; Li, Z.; Wang, T. C.; Hupp, J. T.; Farha, O. K.; Nat. Rev. Mater. 2016, 15018.

68. Choi, H. J.; Dinc, M.; Dailly, A.; Long, J. R.; Energy Environ. Sci. 2010, $3,117$.

69. Sun, L.; Ma, L.; Cai, J.-B.; Liang, L.; Deng, H.; CrystEngComm 2012, $14,890$.

70. Lu, W.; Wei, Z.; Gu, Z.-Y.; Liu, T.-F.; Park, J.; Park, J.; Tian, J.; Zhang, M.; Zhang, Q.; Gentle III, T.; Bosch, M.; Zhou, H.-C.; Chem. Soc. Rev. 2014, 43, 5561.

71. Fordham, S.; Wang, X.; Bosch, M.; Zhou, H.-C. In Lanthanide MetalOrganic Framework; Cheng, P., ed.; Springer: Berlin, 2014; pp. 1-27.

72. Eddaoudi, M.; Moler, D. B.; Li, H.; Chen, B.; Reineke, T. M.; O'Keeffe, M.; Yaghi, O. M.; Acc. Chem. Res. 2001, 34, 319.

73. Janicki, R.; Mondry, A.; Starynowicz, P.; Coord. Chem. Rev. 2017, 340, 98.

74. Chen, Y.; Ma, S.; Rev. Inorg. Chem. 2012, 32, 81.

75. Liu, R.; Yu, T.; Shi, Z.; Wang, Z.; Int. J. Nanomedicine 2016, 11, 1187.

76. Marques, L. F.; Santos, H. P.; Correa, C. C.; Resende, J. A. L. C.; da Silva, R. R.; Ribeiro, S. J. L.; Machado, F. C.; Inorg. Chim. Acta 2016, $451,41$.

77. Lin, Z.; Lü, J.; Hong, M.; Cao, R.; Chem. Soc. Rev. 2014, 43, 5867.

78. Beg, S.; Rahman, M.; Jain, A.; Saini, S.; Midoux, P.; Pichon, C.; Ahmad, F. J.; Akhter, S.; Drug Discovery Today 2016, 0 .

79. Hu, D. X.; Luo, F.; Che, Y. X.; Zheng, J. M.; Cryst. Growth Des. 2007, 7, 1733.

80. Ling, Y.; Jiao, J.; Zhang, M.; Liu, H.; Bai, D.; Feng, Y.; He, Y.; CrystEngComm 2016, 18, 6254.

81. Zhang, Z.; Zheng, Z. In Structure and Bonding; Mingos, D. M. P., ed.; Springer, 2014; Vol. 119, pp. 297-367.

82. Eddaoudi, M.; Kim, J.; Rosi, N.; Vodak, D.; Wachter, J.; O'Keeffe, M.; Yaghi, O. M.; Science 2002, 295, 469.

83. Bunzli, G. J.-C.; Piguet, C.; Chem. Soc. Rev. 2005, 34, 1048.

84. da Silva Viana, R.; Chojnacki, J.; Falcão, E. H. L.; Alves Junior, S.; J. Lumin. 2017, 182, 29. 
85. Wang, S.; Shan, L.; Fan, Y.; Jia, J.; Xu, J.; Wang, L.; J. Solid State Chem. 2017, 245, 132.

86. Batista, P. K.; Alves, D. J. M.; Rodrigues, M. O.; de Sá, G. F.; Junior, S. A.; Vale, J. A.; J. Mol. Catal. A, Chem. 2013, 379, 68.

87. Yan, Z. Q.; Meng, X. T.; Su, R. R.; Zeng, C. H.; Yang, Y. Y.; Zhong, S.; Ng, S. W.; Inorg. Chim. Acta 2015, 432, 41.

88. Ren, Y.; Lu, J.; Jiang, O.; Cheng, X.; Chen, J.; Chin. J. Catal. 2015, 36, 1949.

89. Wanderley, K. A.; Alves Júnior, S.; Paiva-Santos, C. de O.; Quim. Nova 2011, 34, 434

90. Batten, M. P.; Rubio-Martinez, M.; Hadley, T.; Carey, K. C.; Polyzos, K. S. L. A.; Hill, M. R.; Curr. Opin. Chem. Eng. 2015, 8, 55.

91. Walton, K. S.; Snurr, R. Q.; J. Am. Chem. Soc. 2007, 129, 8552.

92. Düren, T.; Millange, F.; Férey, G.; Walton, K. S.; Snurr, R. Q.; J. Phys. Chem. C 2007, 111, 15350

93. Firmino, A. D. G.; Figueira, F.; Tomé, J. P. C.; Paz, F. A. A.; Rocha, J.; Coord. Chem. Rev. 2018, 355, 133.

94. Suescun, L.; Wang, J.; Faccio, R.; Peinado, G.; Torres, J.; Kremer, C.; Burrow, R. A.; Powder Diffr. 2012, 27, 232.

95. Bae, Y.-S.; Dubbeldam, D.; Nelson, A.; Walton, K. S.; Hupp, J. T.; Snurr, R. Q.; Chem. Mater. 2009, 21, 4768.

96. Colombo, V.; Galli, S.; Choi, H. J.; Han, G. D.; Maspero, A.; Palmisano, G.; Masciocchi, N.; Long, J. R.; Chem. Sci. 2011, 2, 1311.

97. Breeze, M. I.; Chamberlain, T. W.; Clarkson, G. J.; de Camargo, R. P.; Wu, Y.; de Lima, J. F.; Millange, F.; Serra, O. A.; O’Hare, D.; Walton, R. I.; Horcajada, P.; Hill, T.; Wilkin, G.; Pedersen, U.; Foster, A.; Maio, N. De; Basham, M.; Yuan, F. J.; Wanelik, K.; CrystEngComm 2017, 19, 2424.

98. Gong, Y. T.; Li, B. H.; Pei, T.; Lin, C. H.; Lee, S.; J. Raman Spectrosc. 2016, 47, 1271.

99. Siberio-pe, D. Y.; Wong-foy, A. G.; Yaghi, O. M.; Matzger, A. J.; Society 2007, 3681.

100. Dutra, J. D. L.; Lima, N. B. D.; Freire, R. O.; Simas, A. M.; Sci. Rep. 2015, 5, 13695

101. Kodaira, C. A.; Brito, H. F.; Malta, O. L.; Serra, O. A.; J. Lumin. 2003 , $101,11$.

102. Butova, V. V; Soldatov, M. A.; Guda, A. A.; Lomachenko, K. A.; Lamberti, C.; Russ. Chem. Rev. 2016, 85, 280.

103. de Sá, G. F.; Malta, O. L.; de Mello Donegá, C.; Simas, A. M.; Longo, R. L.; Santa-Cruz, P. A.; da Silva, E.; Coord. Chem. Rev. 2000, 196, 165.

104. Liu, K.; You, H.; Zheng, Y.; Jia, G.; Song, Y.; Huang, Y.; Yang, M.; Jia, J.; Guo, N.; Zhang, H.; J. Mater. Chem. 2010, 20, 3272.

105. Ramos, A. L. D.; Tanase, S.; Rothenberg, G.; Quim. Nova 2014, 37, 123.

106. D'Vries, R. F.; Gomez, G. E.; Hodak, J. H.; Soler-Illia, G. J. A. A.; Ellena, J.; Dalton Trans. 2016, 45, 646.

107. da Luz, L. L.; Lucena Viana, B. F.; da Silva, G. C. O.; Gatto, C. C.; Fontes, A. M.; Malta, M.; Weber, I. T.; Rodrigues, M. O.; Júnior, S. A.; CrystEngComm 2014, 16, 6914.

108. Qiu, S.; Zhu, G.; Coord. Chem. Rev. 2009, 253, 2891.

109. Harbuzaru, B. V.; Corma, A.; Rey, F.; Jordá, J. L.; Ananias, D.; Carlos, L. D.; Rocha, J.; Angew. Chem., Int. Ed. 2009, 48, 6476.
110. Alduhaish, O.; Li, B.; Nesterov, V.; Arman, H. D.; Alfooty, K.; Asiri, A. M.; Wang, H.; Chen, B.; Inorg. Chem. Commun. 2014, 45, 89.

111. Rocha, J.; Brites, C. D. S.; Carlos, L. D.; Chem. - A Eur. J. 2016, 22, 14782.

112. Brun, N.; Julián-López, B.; Hesemann, P.; Laurent, G.; Deleuze, H.; Sanchez, C.; Achard, M.-F.; Backov, R.; Chem. Mater. 2008, 20, 7117.

113. Heffern, M. C.; Matosziuk, L. M.; Meade, T. J.; Chem. Rev. 2014, 114, 4496.

114. Mikami, K.; Terada, M.; Matsuzawa, H.; Angew. Chem., Int. Ed. 2002, 41, 3554 .

115. Degani, M. S.; Kakwani, M. D.; Palsule Desai, N. H.; Bairwa, R.; Monatsh. Chem. 2012, 143, 461.

116. Aspinall, H. C.; Bickley, J. F.; Greeves, N.; Kelly, R. V.; Smith, P. M.; Organometallics 2005, 24, 3458.

117. Dias, L. C.; de Lucca Jr., E. C.; Ferreira, M. A. B.; Polo, E. C.; J. Braz. Chem. Soc. 2012, 23, 2137.

118. Aguirre-Díaz, L. M.; Iglesias, M.; Snejko, N.; Gutiérrez-Puebla, E.; Monge, M. Á.; $R S C A d v$. 2015, 5, 7058.

119. Vale, J. A.; Faustino, W. M.; Menezes, P. H.; de Sá, G. F.; Chem. Commun. 2006, 3340.

120. Mowry, D. T.; Chem. Rev. 1948, 42, 189.

121. North, M.; Usanov, D. L.; Young, C.; Chem. Rev. 2008, 108, 5146.

122. Abrahams, B. F.; Hoskins, B. F.; Michail, D. M.; Robson, R.; Nature 1994, 369, 727.

123. Rosi, N. L.; Kim, J.; Eddaoudi, M.; Chen, B.; O’Keeffe, M.; Yaghi, O. M.; J. Am. Chem. Soc. 2005, 127, 1504.

124. He, H.; Ma, H.; Sun, D.; Zhang, L.; Wang, R.; Sun, D.; Cryst. Growth Des. 2013, 13, 3154 .

125. Serra, O. A.; Thompson, L. C.; Inorg. Chem. 1976, 15, 504.

126. Peacock, R. D.; Struct. Bonding 1975, 22, 83.

127. Carlos, L. D.; Ferreira, R. A. S.; Bermudez, V. de Z.; Ribeiro, S. J. L.; Adv. Mater. 2009, 21, 509.

128. Cui, Y.; Yue, Y.; Qian, G.; Chen, B.; Chem. Rev. 2012, 112, 1126.

129. Martins, R. F.; Neri, C. R.; de Sousa Filho, P. C.; Serra, O. A.; de Oliveira, K. T.; Quim. Nova 2010, 33, 2118.

130. Bünzli, J.-C. G.; Eliseeva, S. V.; Chem. Sci. 2013, 4, 1939.

131. Carlos, L. D.; Ferreira, R. A. S.; Zéa Bermudez, V. de; Bueno, L. A.; Molina, C.; Messaddeq, Y.; Ribeiro, S. J. L.; Quim. Nova 2001, 24, 453.

132. Weber, I. T.; de Melo, A. J. G.; Lucena, M. A. de M.; Rodrigues, M. O.; Alves Junior, S.; Anal. Chem. 2011, 83, 4720.

133. Reis, E. L. T. dos; Sarkis, J. E. de S.; Rodrigues, C.; Negrini Neto, O.; Viebig, S.; Quim. Nova 2004, 27, 409.

134. Roy, S.; Chakraborty, A.; Maji, T. K.; Coord. Chem. Rev. 2014, 273-274, 139.

135. Wang, Y.; Yang, J.; Liu, Y. Y.; Ma, J. F.; Chem. - Eur. J. 2013, 19, 14591.

136. Falcaro, P.; Ricco, R.; Yazdi, A.; Imaz, I.; Furukawa, S.; Maspoch, D.; Ameloot, R.; Evans, J. D.; Doonan, C. J.; Coord. Chem. Rev. 2016, 307, 237.

137. Stock, N.; Biswas, S.; Chem. Rev. 2012, 112, 933.

138. Cohen, S. M.; Chem. Rev. 2012, 112, 970. 